NBER WORKING PAPER SERIES

\title{
DIFFERENCES OF OPINION AND INTERNATIONAL EQUITY MARKETS
}

\author{
Bernard Dumas \\ Karen K. Lewis \\ Emilio Osambela \\ Working Paper 16726 \\ http://www.nber.org/papers/w16726
NATIONAL BUREAU OF ECONOMIC RESEARCH
1050 Massachusetts Avenue
Cambridge, MA 02138
January 2011

For valuable suggestions, we thank Geert Bekaert, Urban Jermann, Leonid Kogan, Stavros Panageas, Anna Pavlova, Raman Uppal, Frank Warnock, Wei Xiong, and three anonymous referees. We are also grateful for comments from participants at presentations given at the University of Pennsylvania Wharton School, HEC Lausanne, the CEPR Fourth Annual Workshop on Global Interdependence at the European University Institute, the 8th Annual Swiss Doctoral Workshop in Finance at Gerzensee, the NBER meeting of International Finance and Macroeconomics, Princeton University, Carnegie Mellon University, the Adam Smith Asset Pricing Conference at the Oxford-Man Institute, the American Finance Association annual meeting, University of Houston, the 10th Annual Darden International Finance Conference, University of Southern California, McGill University, Cornell University, the Society for Economic Dynamics annual meeting, the Federal Reserve Bank at Dallas, University of Calgary, University of Texas at Dallas, Rutgers University, and the Federal Reserve Board. We thank Frank Warnock and Stephanie Curcuru for advice with reconstructing the US net equity purchases data, Ivan Shaliastovich for the forecast variance data, and Xiang Fang for excellent research assistance. Dumas and Osambela gratefully acknowledge the financial support from NCCR FINRISK of the Swiss National Science Foundation. Dumas is also grateful for the hospitality of Collegio Carlo Alberto, and for the support from: the INSEAD research fund, BI Norwegian Business School, and the AXA Chair in Socioeconomic Risks at the University of Torino. Lewis acknowledges funding from the National Science Foundation and the Wharton-SMU Research Center with thanks. The views expressed herein are those of the authors and do not necessarily reflect the views of the National Bureau of Economic Research.

NBER working papers are circulated for discussion and comment purposes. They have not been peerreviewed or been subject to the review by the NBER Board of Directors that accompanies official NBER publications.

(C) 2011 by Bernard Dumas, Karen K. Lewis, and Emilio Osambela. All rights reserved. Short sections of text, not to exceed two paragraphs, may be quoted without explicit permission provided that full credit, including $\odot$ notice, is given to the source. 
Differences of Opinion and International Equity Markets

Bernard Dumas, Karen K. Lewis, and Emilio Osambela

NBER Working Paper No. 16726

January 2011, Revised May 2016

JEL No. F3,G11,G12,G15

\begin{abstract}
$\underline{\text { ABSTRACT }}$ proxies are consistent with the model.

Bernard Dumas

INSEAD

boulevard de Constance

77305 Fontainebleau Cedex

FRANCE

and NBER

bernard.dumas@insead.edu

Karen K. Lewis

Department of Finance, Wharton School

$2300 \mathrm{SHDH}$

University of Pennsylvania

Philadelphia, PA 19104-6367

and NBER

lewisk@wharton.upenn.edu

\author{
Emilio Osambela \\ Tepper School of Business \\ Carnegie Mellon University \\ 5000 Forbes Avenue \\ Pittsburgh, PA 15213 \\ osambela@cmu.edu
}

We develop an international financial market model in which domestic and foreign residents differ in their beliefs about the information content in public signals. We determine how informational advantages by domestic investors in the interpretation of home public signals impact equity markets. We evaluate the ability of our model to generate four international finance anomalies: (i) the co-movement of returns and capital flows; (ii) home-equity preference; (iii) the dependence of firm returns on home and foreign factors; and (iv) abnormal returns around foreign firm cross- listing in the home market. Their relationships with empirical differences-of-opinion 
"In almost all models of economic theory, behavioral differences among consumers are attributed to differences in preferences or in the information they possess. In real life, differences in consumer behavior are often attributed to varying intelligence and ability to process information. Agents reading the same morning newspapers with the same stock price lists will interpret the information differently."

Ariel Rubinstein (1993) cited by Kandel and Pearson (1995).

How do differences in interpreting the same information affect financial markets? This question is at the core of a growing Difference-of-Opinion (hereafter DOO) literature. While differing opinions may exist between agents in any market, international markets provide a natural place to study their effects. Evidence of financial market segmentation across countries has been documented extensively, with different perceptions across those countries often cited as a source. Perhaps people of different countries harbor different opinions that affect their ability to process information relevant to the analysis of economies other than their own. As such, the international financial market may be viewed as a natural laboratory for analyzing the effects of differing opinions.

In this paper, therefore, we propose a fully dynamic DOO model based upon international differences in perceptions about economic information, incorporating the equilibrium consumption of utility-maximizing investors. We assume that home investors are better at understanding home signals, and, as such, are rational about home information. However, investor groups in both countries misinterpret the information about the other country's prospective growth and are, therefore, equally rational or irrational. We call this new feature "foreign sentiment."

The information assumption captures the idea that, while foreigners may see home information as well as home residents do, they do not know how to interpret it. The assumption may be motivated (in an unmodeled way) in at least three different ways, all stemming from the hypothesis that investors start history with priors that ignore the relationships (i.e., correlations) between the signals and the growth rates, and gradually discover them as data comes in. First, it could be that home investors have had a longer time to study the relationship. From this perspective, it may be taking foreigners a longer time to learn how to interpret the home signal and, if so, our model is analyzing a long 
transitional time period. Second, foreigners may simply have chosen not to become informed about the signal because they have viewed home investment as too risky in the past and consider becoming informed too costly. ${ }^{1}$ Third, foreign investors may not be able to learn the same information as home residents. ${ }^{2}$ The assumption can also be viewed as a natural extension of the Merton (1987) "investor-recognition" hypothesis, to which we add the explicit modelling of information processing. ${ }^{3}$ In Section 1, we review the empirical evidence found in the extant literature that supports the DOO hypothesis.

To highlight the effects of DOO, we embed our information processing in a two-country model that is otherwise as stylized and parsimonious as possible. Each country has an output process with an unobserved conditional mean that can be inferred from observable outputs and signals, each generated by subjective Brownian motions. Moreover, markets are complete and all information is public. Investors in each country have an identical set of five assets that complete the market: a riskfree asset, two equities with payoffs in the output process in each country, and two futures contracts with payoffs marked to signal innovations. The manner in which information is processed by investors is modelled in Section 2 and the equilibrium is calculated in Section 3.

We then ask to what extent our model can produce international empirical regularities related to asset pricing, portfolio choices and capital flows. For that purpose, we gather data, described in Section 4.1, to re-estimate standard empirical relationships in the literature, allowing comparison with simulated data from our model. After examining the implications of the model and parameter values for some traditional moments of asset prices, capital flows, output and consumption (Section 4), we evaluate the effects of DOO on four known empirical regularities. Two of these relationships have been found at the country level (Section 5). The first of these empirical regularities is the positive relationship between foreign capital inflows and home stock returns, sometimes called "return-

\footnotetext{
${ }^{1}$ For example, Van Nieuwerburgh and Veldkamp (2009) show in a noisy-rational-expectations model that, when investors are endowed with a small home information advantage, they choose not to learn what foreigners know.

${ }^{2}$ Acemoglu, Chernozhukov, and Yildiz (2015) show that when agents are uncertain about the conditional distribution, even a small amount of uncertainty can lead to significant differences in long-run beliefs.

${ }^{3}$ On the investor-recognition hypothesis, see also the empirical work of Lehavy and Sloan (2008), and Richardson, Sloan and You (2012).
} 
chasing." We show that our model implies this same co-movement when home investors have an informational advantage in interpreting home signals. For the second regularity, we examine "homeequity preference," the observation that home residents weight home assets more heavily than foreign assets in their portfolios. Since home investors ignore foreign signals in our model, they shy away from holding foreign equity because they perceive higher sensitivity of the foreign stock return to foreign dividend shocks. Therefore, our model generates this relationship as well.

Next we analyze the other two regularities based upon firm-level pricing observations (Section 6). For this purpose, we introduce an additional equity from a new firm we call the "home firm" that operates in the home market. We first evaluate the finding that home firm returns depend upon both home- and foreign-market factors. Using our extended model, we show that foreign sentiment risk indeed generates a home-and foreign-factor model in consumption. We also show that regressing our firm-level excess returns on the home and foreign country stock excess returns implies a somewhat higher beta on the home market than the foreign market, consistent with typical empirical findings. We then move to our next pricing observation: stock prices on home firms that cross-list in foreign markets tend to increase around this event, and expected returns decline thereafter, responses often attributed to increased information to foreign investors about the cross-listed firms. To examine this effect in our model, we conjecture that cross-listing by the home firm in the foreign market enables the foreign country's investor to correctly interpret information about the home firm. Because crosslisting aligns perceptions about the information in public signals, the resulting decline in disagreement risk decreases the required return and increases the price, as in the data.

Simulations show that the model can qualitatively generate all four of these regularities with varying degrees of quantitative success. In addition, the model suggests several empirical relationships across countries and firms depending upon their sensitivity to measures of DOO. Using dispersion in professional forecasts of economic activity to examine these relationships, we find evidence consistent with our model.

Overall, our paper provides a significant contribution on at least three fronts. First, we present 
the first two-country general equilibrium model in which investors have heterogeneous confidence about public information. On the technical side, we extend the model by Dumas, Kurshev and Uppal (2009) to a multiple-trees setup. ${ }^{4}$ Second, to our knowledge, this paper provides the first informationbased attempt to explain the above four international empirical regularities simultaneously. Third, we provide new empirical evidence that DOO may affect these regularities.

\section{The difference-of-opinion hypothesis}

In this section, we argue that the DOO hypothesis is a legitimate contender as an explanation of phenomena in the financial market and that it deserves examination, alongside the alternative hypothesis that says that different people receive different, private information. ${ }^{5,6}$ Indeed, a growing body of direct and indirect empirical evidence suggests that differences of opinion play an important role.

Direct evidence is provided by data on professional forecasters, of the kind we explore in Section 7 . Patton and Timmermann (2010) show that differences in individual-forecaster views persist through time. Based on a statistical model of the effect of public vs. private information, they conclude that "such differences in opinion cannot be explained by differences in information sets; our results indicate they stem from heterogeneity in priors or models." They also observe (as do Dovern, Fritsche and Slacalek (2012)) that "Differences in opinion move countercyclically, with heterogeneity being strongest during recessions where forecasters appear to place greater weight on their prior beliefs." It would be hard to imagine that more private information induces forecasters to disagree more during

\footnotetext{
${ }^{4}$ Cochrane, Longstaff and Santa Clara (2008), and Martin (2013) show that this extension is already far from trivial with homogeneous investors. Osambela (2015) considers a model with two trees, DOO, and funding liquidity constraints, but with deterministic disagreement. To our knowledge, we are the first to solve a multiple-trees model in a setup with DOO and stochastic disagreement, driven by heterogeneous confidence in public signals. Moreover, in Appendix B, we extend the model to correlated trees, still yielding explicit solutions.

${ }^{5}$ Previous contributions to the DOO approach include: Harris and Raviv (1993) and Cecchetti, Lam and Mark (2000). See Morris (1995) for a discussion of this approach.

${ }^{6}$ In both approaches, investors learn about the current state of the economy, knowing exactly how the economy operates, although they do not observe it completely. In yet a third approach, called "parameter uncertainty," investors are uncertain about the parameters of the model that govern the economy. See Collin-Dufresne, Lochstoer and Johannes (2015).
} 
recessions than during expansions whereas, in our DOO model, disagreement and output growth are found to be correlated, in conformity with that observation. ${ }^{7}$

Indirect evidence comes from the observed relationship between volume of trading and returns in the stock market at the time of public announcements of quarterly earnings. In a sample of more than 60,000 firm/announcements, Kandel and Pearson (1995) find that, around a public announcement date, the relationship between volume of trade and returns is clearly different from what it is at other times. They consider many candidate models for the treatment of information by investors, trying to fit them to the observed relationship and conclude that "it is inconsistent with most existing models in which agents have identical interpretations of the public announcement." 8 Bamber, Barron and Stober (1999) directly test the relationship between trading volume and a proxy for the measure of differential interpretations that had been suggested by Kandel and Pearson (1995). They find that "around earnings announcements that generate minimal price changes (where many models predict there should be no information-based trading) trading volume increases significantly with Kandel and Pearson's measure of differential interpretations." 9 In the international sphere, the dramatic capital flow waves - classified as "surges, stops, flight, and retrenchment" - that Forbes and Warnock (2011) examine make sense if we consider that home and foreign investors hold different and highly fluctuating views about a country's growth prospects, about which there is unlikely to exist much private information.

\footnotetext{
${ }^{7}$ Avramov, Kaplanski and Levy (2015) show that the recommendations of analysts who rely on technical analysis are superior to those relying on fundamental analysis. They both have access to public information but the former, by construction, use public information only and process it differently.

${ }^{8}$ Similarly, earlier work by Kim and Verrecchia (1991) concluded that differential interpretations had to be present to some degree.

${ }^{9}$ Motivated by findings such as these, Cao and Ou-Yang (2008) analyze the effects of disagreement about volatilities upon the pricing of options. Private information about volatilities is hard to come by. In a very recent paper, Jia, Wang and Xiong (2015) compare the empirical reactions of Chinese and foreign investors to the same public news. They find that Chinese investors react more strongly to earnings forecast revisions published by Chinese analysts while foreign investors react more strongly to revisions published by foreign analysts. Individual household portfolios provide separate and complementary evidence about differences of opinion. In a panel-data analysis of Norwegian household portfolios, Doskeland and Hvide (2011) find preference both in holdings and in trades for the equity of the householder's employer. With no return-based evidence of informational advantage, this phenomenon looks similar to home-equity preference. They conclude that "Overconfidence seems the most likely explanation for the excessive trading in professionally close stocks."
} 
Further indirect evidence for differences of opinion can also be found in commodity markets. Singleton (2014) observes a positive price drift (which he calls a "boom") in commodities prices - reflecting an additional risk premium - during periods when there is more disagreement among analysts' forecasts. This finding is directly in line with our DOO theory, which says that more disagreement implies more volatility in sentiment risk.

Models that rely on private information - such as Noisy Rational Expectations (NRE) models have also been used to explain two of the empirical regularities we study - capital flows and homeequity preference. Early models about these regularities typically assumed that the informational advantage to home residents arises from more precise, privately observed signals. For example, Gehrig (1993) posits that home residents have more certainty about home fundamentals information than do foreigners, thereby reducing the optimal holdings of foreign assets. ${ }^{10}$

Brennan and Cao (1997), in a model in which investors have initially received private signals, show that foreign purchases of home equities are positively correlated with home stock returns, because they both react the same way to public signals. In our DOO model, instead of receiving initial private signals, different investors make different assumptions about parameters; but the reaction to public information is very similar.

An important difference introduced by our model is the endogenization of the rate of interest. To our knowledge, all extant implementations of NRE assume an exogenous and constant rate of interest, so that they are not fully general-equilibrium models. As Loewenstein and Willard (2006) pointed out, this assumption implies that capital goes in and out of a storage facility that returns the fixed rate of interest, thereby affecting the implied behavior of capital flows. Albuquerque, Bauer and Schneider (2007) present an NRE model that delivers persistence of net capital flows, as in the data. ${ }^{11}$ The serial dependence of capital flows between investors or between countries when the rate

\footnotetext{
${ }^{10}$ Many NRE models rely on the presence of noise traders - a behavioral feature. That assumption has been relaxed by Wang (1994) and Hatchondo, Krusell and Schneider (2014).

${ }^{11}$ The articles by Dvořák (2003), Albuquerque, Bauer and Schneider (2007, 2009) and Hau and Rey (2008) all highlight the need to study not just a country's international capital flows but also the gross flows into the various securities of one country executed by investors who differ from each other within each country. In order to explain simultaneous foreign purchases and sales, they argue that some US investors must be transacting with other US investors and, therefore,
} 
of interest is held fixed is presumably quite different than when the rate of interest is endogenous. ${ }^{12}$ Indeed, we demonstrate below that our DOO model can explain only a small degree of capital flow persistence, in part due to the adjustment in the rate of interest.

Overall, our endeavor below is not predicated on an assertion that the DOO approach is better than the NRE approach in explaining the international phenomena we study, or that these international phenomena provide a way to discriminate between the two approaches. Nothing at this point positions one approach as the incumbent and the other as the challenger. Indeed, it seems plausible that both differences of opinion and asymmetric information are important forces in the market.

\section{The foreign sentiment risk model: information processing}

In this section, we provide a simple framework that captures two features. First, the information in current economic variables and public signals affects forecasts of future variables and hence current prices of financial securities. And, second, investors differ across countries in their beliefs about the informativeness of these currently observed public signals.

The basic features of these differing beliefs and their impact on future expectations can be shown most parsimoniously using a model with two ex ante identical countries. Representative investors live in each of the two countries. The countries are completely integrated in that they are open to international trade in securities and in a single, perishable good. Investors in each country are initially endowed with one share of their own output process, itself initialized at the value 1 . The financial market is complete.

introduce two types of investors within a country. In our paper, by contrast, we consider transactions on only one firm per country, summarizing the net securities transactions within that country. In principle, our dynamic equilibrium could also be extended to any number of investors and securities. This extension would necessarily complicate the model and likely make the DOO channel less transparent. We therefore leave this topic for future research.

${ }^{12}$ Admittedly, our rate of interest is too volatile (see Panel A of Table 2). The sentiment-risk model produces too much volatility in one place and/or not quite enough in another, which is why some articles on the subject have either examined the equity market without looking at the bond market or vice-versa. 


\subsection{Exogenous outputs and public signals}

The output delivered by Country $i \in\{A, B\}$ at time $t$ is denoted $\delta_{i, t} d t$. The stochastic process for $\delta_{i, t}$ is

$$
\frac{d \delta_{i, t}}{\delta_{i, t}}=f_{i, t} d t+\sigma_{\delta} d z_{i, t}^{\delta}, \quad i \in\{A, B\}
$$

where $z_{i}^{\delta}$ are Brownian motions under the objective probability measure, which governs empirical realizations of the process. The conditional growth rates $f_{i, t}$ of outputs are also stochastic:

$$
d f_{i, t}=\zeta\left(\bar{f}-f_{i, t}\right) d t+\sigma_{f} d z_{i, t}^{f}, \quad i \in\{A, B\},
$$

where $\zeta>0$ and $z_{i}^{f}$ are also Brownian motions under the objective probability measure.

Neither the conditional growth rates of outputs $f_{i}$ nor the $z$ shocks are observed by any investor. All investors must estimate, or filter out, the current value of $f_{i}$ in order to determine the way future conditional mean growth rates affect forward-looking asset prices. They estimate this value by observing current outputs and two public signals $\left(s_{A}, s_{B}\right)$. The signals follow the processes

$$
d s_{i, t}=\phi d z_{i, t}^{f}+\sqrt{1-\phi^{2}} d z_{i, t}^{s}, \quad i \in\{A, B\}
$$

where $|\phi| \in[0,1]$ and where $z_{i}^{s}$ is a third pair of Brownian motions, under the objective probability measure as well. The term $\phi d z_{i, t}^{f}$ in the stochastic differential equation for the signals means that the signals are truly informative about output growth shocks $d z_{i, t}^{f}$.

For expositional purposes, we describe in the text the model assuming that the six Brownian motions $\left(z_{A, t}^{\delta}, z_{A, t}^{f}, z_{A, t}^{s}, z_{B, t}^{\delta}, z_{B, t}^{f}, z_{B, t}^{s}\right)$ are independent of each other. As we show below, this independence, together with symmetry, provides a significantly simplified version of our model with an intuitive solution. For our quantitative analysis below, we allow for cross-country output correlation, however. Details of the solution with output correlation are provided in Appendix B.

Note that, in these output and signal processes, the parameters are identical across countries for 
symmetry. Thus, the volatility of the outputs and conditional growth rates, $\sigma_{\delta}$ and $\sigma_{f}$, the longrun means of the conditional growth rates and their mean reversion parameters, $\bar{f}$ and $\zeta$, and the information in the signal, $\phi$, do not depend upon the country.

\subsection{Benchmark beliefs: the viewpoint of the "econometrician"}

In the information model we develop below, no investor knows the true state of the economy. We consider as a benchmark the perspective taken by a nonexistent being who interprets data correctly and whom we call "the econometrician." This abstract agent is not a participant in our economy. As in Xiong and Yan (2010), the econometrician observes the same information as do both sets of investors. Like the investors of both countries, the econometrician does not observe the true conditional growth rate of outputs and must filter out this process. The econometrician's measure, therefore, is not the same as the objective probability measure under which we wrote Equations (1), (2) and (3). The difference between the two measures is the observation or non observation of state variables, $\left\{f_{i, t}\right\}_{i \in\{A, B\}}$.

We assume, however, that the econometrician knows the true structure of the economy (Equations (1), (2) and (3)). Accordingly, the econometrician filters the signal process under the hypothesis stated in Equation (3). We formulate the probability measures of home and foreign groups as deviations from the econometrician's probability measure.

To calculate the econometrician's probability measure, we rewrite the stochastic differential equations in terms of processes that are Brownian motions under his probability measure. For this purpose, we define the four-dimensional process $w_{t}^{E}=\left(w_{\delta_{A}, t}^{E}, w_{\delta_{B}, t}^{E}, w_{s_{A}, t}^{E}, w_{s_{B}, t}^{E}\right)^{\top}$, where each of the elements of $w_{t}^{E}$ corresponds to a Brownian motion of each of the four observed variables under the probability measure of the econometrician. Defining $\widehat{f}_{i, t}^{E}$ as the conditional mean of the growth rate of output in Country $i$ as estimated by the econometrician, we use filtering theory (see Lipster and Shiryaev (2000, Theorem 12.7, page 36)) to compute these conditional expected values. For $i \in\{A, B\}$, these 
expectations are given by

$$
d \widehat{f}_{i, t}^{E}=\zeta\left(\bar{f}-\widehat{f}_{i, t}^{E}\right) d t+\frac{\gamma^{E}}{\sigma_{\delta}} d w_{\delta_{i}, t}^{E}+\phi \sigma_{f} d w_{s_{i}, t}^{E}
$$

where the number $\gamma^{E}$ is the steady-state variance of the econometrician's forecast errors $\widehat{f}_{A}^{E}-f_{A}$ and $\widehat{f}_{B}^{E}-f_{B}$, these variances being equal to each other by virtue of symmetry:

$$
\gamma^{E} \triangleq \sigma_{\delta}^{2}\left(\sqrt{\zeta^{2}+\left(1-\phi^{2}\right) \frac{\sigma_{f}^{2}}{\sigma_{\delta}^{2}}}-\zeta\right)
$$

This variance would normally be a deterministic function of time. But for simplicity we assume, as did Scheinkman and Xiong (2003) and Dumas, Kurshev and Uppal (2009), that there has been a sufficiently long period of learning for people of both countries to converge to their long-run level of variance, independent of their prior.

Equation (4) shows how the econometrician filters out the conditional growth rates based upon observations of outputs and signals. When he sees an increase in the output of Country $i$, he updates his estimate of the conditional mean growth rate by the ratio of its steady state variance $\gamma^{E}$ and the variance of the output $\sigma_{\delta}$. When he sees an increase in the signal of Country $i$, he increases his view of $f_{i, t}$ according to $\phi \sigma_{f}$, the information precision in the signal about this growth rate.

By definition of the growth rates $\widehat{f}_{A, t}^{E}$ and $\widehat{f}_{B, t}^{E}$, we can then write under the econometrician's measure:

$$
\frac{d \delta_{i, t}}{\delta_{i, t}}=\widehat{f}_{i, t}^{E} d t+\sigma_{\delta} d w_{\delta_{i}, t}^{E}, i \in\{A, B\}
$$

\subsection{The investors' viewpoints}

The difference in information processing by the investors of the two countries is implemented as follows. Investors in Country $A$ perform their filtering under the belief that the signal $s_{A}$ has the correct conditional correlation with $f_{A}$ but they believe incorrectly that the signal $s_{B}$ has zero correlation 
with $f_{B}$. The "model" they have in mind is

$$
d s_{A, t}=\phi d z_{A, t}^{f}+\sqrt{1-\phi^{2}} d z_{A, t}^{s}, \quad d s_{B, t}=d z_{B, t}^{s} .
$$

Notice that investors in Country $A$ have the same model of signal $s_{A}$ as the econometrician (incorporating the true correlation $\phi$ in Equation (3)) but a different one (incorporating a correlation equal to zero) for the signal $s_{B}$. Symmetrically, the "model" that investors of Country $B$ have in mind is

$$
d s_{A, t}=d z_{A, t}^{s}, \quad d s_{B, t}=\phi d z_{B, t}^{f}+\sqrt{1-\phi^{2}} d z_{B, t}^{s} .
$$

Defining $\widehat{f}_{j}^{i}$ as the conditional mean of the output growth in Country $j$ as estimated by investors in Country $i$, we implement filtering theory one more time to write

$$
\begin{aligned}
& d \widehat{f}_{i, t}^{i}=\zeta\left(\bar{f}-\widehat{f}_{i, t}^{i}\right) d t+\frac{\gamma^{E}}{\sigma_{\delta}^{2}}\left(\frac{d \delta_{i, t}}{\delta_{i, t}}-\widehat{f}_{i, t}^{i} d t\right)+\phi \sigma_{f} d s_{i, t} \\
& d \widehat{f}_{j, t}^{i}=\zeta\left(\bar{f}-\widehat{f}_{j, t}^{i}\right) d t+\frac{\gamma^{\times}}{\sigma_{\delta}^{2}}\left(\frac{d \delta_{j, t}}{\delta_{j, t}}-\widehat{f}_{j, t}^{i} d t\right), i \neq j
\end{aligned}
$$

where the number $\gamma^{\times}$is the steady-state variance of the "transnational" forecast errors $\widehat{f}_{A}^{B}-f_{A}$ and $\widehat{f}_{B}^{A}-f_{B}$, their variances being equal to each other by virtue of symmetry:

$$
\gamma^{\times}=\left.\gamma^{E}\right|_{\phi=0}=\sigma_{\delta}^{2}\left(\sqrt{\zeta^{2}+\frac{\sigma_{f}^{2}}{\sigma_{\delta}^{2}}}-\zeta\right) .
$$

Note from Equation (5) that $\gamma^{E}$ decreases as the information in the signal measured by $\phi^{2}$ rises toward one. Intuitively, the signal $s_{i}$ allows the econometrician and investors in Country $i$ to get a more precise estimate of $f_{i}$, thereby reducing the steady-state variance for investors in Country $i$ 's estimate. By contrast, investors in Country $j \neq i$ ignore the information in the signal $s_{i}$ and thereby attribute more of the variability to $f_{i}$. The result is a relationship we use below:

Proposition 1 The steady-state variance of the forecast error of the home-output growth rate made 
by home investors is lower than the steady-state variance of the same forecast error made by foreign investors; i.e., $\gamma^{E}<\gamma^{\times}=\left.\gamma^{E}\right|_{\phi=0}$.

Since the econometrician's hypothesis about signals is not in line with that of investors in any of the two countries, differences in beliefs are generated. We define the "disagreements" between the econometrician and the investors as

$$
\widehat{g}_{i}^{j} \equiv \widehat{f}_{i, t}^{E}-\widehat{f}_{i, t}^{j} ; \quad i, j \in\{A, B\}
$$

In principle, $\widehat{g}_{i}^{j}$ stands for two pairs of disagreements for each country's investor. However, the investors agree with the econometrician about the estimate of the conditional growth rate of their own output. Therefore, $\widehat{g}_{A}^{A} \equiv \widehat{f}_{A, t}^{E}-\widehat{f}_{A, t}^{A}=0$ and $\widehat{g}_{B}^{B}=\widehat{f}_{B, t}^{E}-\widehat{f}_{B, t}^{B}=0$ so that only $\widehat{g}_{A}^{B} \equiv \widehat{f}_{A, t}^{E}-\widehat{f}_{A, t}^{B}$ and $\widehat{g}_{B}^{A} \equiv \widehat{f}_{B, t}^{E}-\widehat{f}_{B, t}^{A}$, the disagreements between the econometrician and the foreign investor's forecast of the home output growth rate, move over time. ${ }^{13}$ Using equations (9), (10) and (11) we get the dynamics for the disagreements

$$
d \widehat{g}_{i, t}^{j}=-\left(\zeta+\frac{\gamma^{\times}}{\sigma_{\delta}^{2}}\right) \widehat{g}_{i, t}^{j} d t+\frac{\gamma^{E}-\gamma^{\times}}{\sigma_{\delta}} d w_{\delta_{i}, t}^{E}+\phi \sigma_{f} d w_{s_{i}, t}^{E} ; \quad i \neq j ; \quad i, j \in\{A, B\}
$$

The econometrician's and investor's filters in Equations (4) and (10), respectively, make clear the drivers for the disagreements in Equation (12). On the one hand, a positive output shock of, say, Country $A, d w_{\delta_{A}, t}^{E}$, causes the econometrician to increase his estimate $\widehat{f}_{A}^{E}$ according to $\frac{\gamma^{E}}{\sigma_{\delta}}$. This same output change induces investors in Country $B$ to increase their estimate by $\frac{\gamma^{\times}}{\sigma_{\delta}}$. Recall that $\gamma^{\times}>\gamma^{E}$ (Proposition 1): because these investors ignore the signal information, they update their estimate by more than the econometrician (and more than investors in Country $A$ ). Thus, Country $B$ investors over-adjust their estimate of Country $A$ output growth in response to its output shock

\footnotetext{
${ }^{13}$ When output is correlated, however, both pairs of disagreement move over time and are jointly persistent. See Appendix B for details.
} 
and the disagreement between these investors and the econometrician declines, $d \widehat{g}_{A, t}^{B}<0$. Given the definition in Equation (11), this relationship means that Country B investors become relatively optimistic about Country $A$ output. On the other hand, an increase in the signal $d w_{s_{A}, t}^{E}$ induces the econometrician to increase his estimate of the conditional mean $\widehat{f}_{A}^{E}$ in Equation (4). Since Country $B$ investors ignore the signal information, the signal increases the disagreement about Country $A$ output, $d \widehat{g}_{A, t}^{B}>0$. Country $B$ investors become relatively pessimistic about Country $A$. This insight leads to the following proposition.

Proposition 2 Foreign investors under-adjust their estimate of home output growth in response to home signal shocks and over-adjust their estimate of home output growth in response to home output shocks. By contrast, home investors adjust properly their own output growth rate estimate in response to both home output and home signal shocks.

We now derive the changes in measures between the econometrician and investors. For this purpose, consider also a set of four-dimensional processes for each country that is Brownian under the probability measure of investors in Country $j ; w_{t}^{j}=\left(w_{\delta_{A}, t}^{j}, w_{\delta_{B}, t}^{j}, w_{s_{A}, t}^{j}, w_{s_{B}, t}^{j}\right), j \in\{A, B\}$. These processes differ from the econometrician's according to

$$
d w_{\delta_{i}, t}^{E}=d w_{\delta_{i}, t}^{j}-\frac{\widehat{g}_{i, t}^{j}}{\sigma_{\delta}} d t, \quad d w_{s_{i}, t}^{E}=d w_{s_{i}, t}^{i}
$$

The probabilities of events will look different from the point of view of the econometrician and the investors in the two countries. The change in measure between the sets of Brownians perceived by the econometrician, $w_{t}^{E}$, and by the investor in country $j, w_{t}^{j}$, indicates the evolution of their difference in beliefs. Based on Equation (13), we can apply Girsanov's theorem to obtain the changes from the probability measure of the econometrician to those of investors in Country $A$ and $B$. Doing so implies that the ratios of probability beliefs between these countries evolve according to:

$$
d \eta_{A, t}=-\frac{\widehat{g}_{B, t}^{A}}{\sigma_{\delta}} \eta_{A, t} d w_{\delta_{B}, t}^{E}, \quad d \eta_{B, t}=-\frac{\widehat{g}_{A, t}^{B}}{\sigma_{\delta}} \eta_{B, t} d w_{\delta_{A}, t}^{E}
$$


We give the ratio of beliefs $\eta_{i}$ the picturesque name of "Country $i$ foreign sentiment" or, more generally, "foreign sentiment risk". By contrast the stochastic term in the disagreement equation (12) is referred to as "disagreement risk". Equations (14) show the following:

Proposition 3 The foreign sentiment risk of the investors of one country is perfectly correlated with the output shock of the other country (with the sign of the perfect correlation being opposite to the sign of current disagreement).

Notice that the ratios of probability beliefs are not impacted by signal shocks. Also, the evolution of $\eta_{A, t}$ does not depend upon the Country $A$ output shock since the econometrician and the Country $A$ investors agree about the filter of that process. ${ }^{14}$ The change of measure between an investor of a country and the econometrician is perfectly (positively or negatively) correlated with the output in the other country. Disagreements $\widehat{g}_{B, t}^{A}$ and $\widehat{g}_{A, t}^{B}$ are the drivers of the instantaneous volatilities of the foreign sentiment variables. For example, $\eta_{A, t}$ depends upon realizations of the output in Country $B$, according to $d w_{\delta_{B}, t}^{E}$. The size of this effect depends upon the current disagreement between the econometrician and investors in Country $A, \widehat{g}_{B, t}^{A}$. If investors in Country $A$ are currently optimistic about Country $B$, then $\widehat{g}_{B, t}^{A}<0$. Since Country $A$ investors over-adjust their estimate of Country $B$ output growth in response to its output realizations, this response will further increase the difference in probabilities and $\eta_{A, t}$ increases.

The Markovian system comprised of Equations (4), (6), (12), and (14) completely characterizes the dynamics of eight exogenous state variables that drive the economy, defined by the vector: $Y_{t} \equiv$ $\left(\delta_{A, t}, \widehat{f}_{A, t}^{E}, \widehat{g}_{A, t}^{B}, \eta_{B, t}, \delta_{B, t}, \widehat{f}_{B, t}^{E}, \widehat{g}_{B, t}^{A}, \eta_{A, t}\right)^{\top}$. However, since outputs are uncorrelated, the first four components of the vector are only driven by the Brownians on the output and signal of Country $A$, while the last four components of the vector are driven by the corresponding Brownians for Country

\footnotetext{
${ }^{14}$ When output is correlated, however, these correlations generate disagreement between each investor and the econometrician about both output growth rates. See Appendix B for details.
} 
$B$. Therefore, the state vector can be written as two independent processes: $Y_{t}=\left\{Y_{A, t}, Y_{B, t}\right\}$ where

$$
Y_{i, t}=\left\{\delta_{i, t}, \widehat{f}_{i, t}^{E}, \widehat{g}_{i, t}^{j}, \eta_{j, t}\right\}^{\top}
$$

for $i, j \in\{A, B\} ; i \neq j$. Although they have equal diffusion matrices, each of these two processes is driven by separate Brownians. In particular,

$$
d Y_{i, t}=\mu_{i, t} d t+\Omega_{i, t} d w_{i, t}^{E}
$$

where

$$
d w_{i, t}^{E}=\left\{d w_{\delta_{i}, t}^{E}, d w_{s_{i}, t}^{E}\right\}
$$

and

$$
\Omega_{i, t}=\left[\begin{array}{cc}
\sigma_{\delta} \delta_{i, t} & 0 \\
\left(\frac{\gamma^{E}}{\sigma_{\delta}}\right) & \phi \sigma_{f} \\
\left(\frac{\gamma^{E}-\gamma^{\times}}{\sigma_{\delta}}\right) & \phi \sigma_{f} \\
-\eta_{j, t}\left(\frac{\widehat{g}_{i, t}^{j}}{\sigma_{\delta}}\right) & 0
\end{array}\right], i \neq j .
$$

Thus, the state vector can be evaluated as two independent processes, each governing the evolution of views about each country's output, providing a block diagonal structure exploited in our description of the equilibrium below. This convenient block diagonal structure no longer holds when output are correlated, as we describe in Appendix B.

\section{The foreign sentiment risk model: equilibrium}

We now use the information structure to derive equilibrium pricing relationships. The derivation of equilibrium in a complete market is standard.

The investors in the two countries have identical time-separable utility functions in a common 
perishable consumption good. For Country $B$ investors, the problem can be written as

$$
\sup _{c_{B}} \mathbb{E}_{0}^{E} \int_{0}^{\infty} \eta_{B, t} e^{-\beta t} \frac{1}{\alpha} c_{B, t}^{\alpha} d t, \quad \alpha<1
$$

subject to the lifetime budget constraint:

$$
\mathbb{E}_{0}^{E} \int_{0}^{\infty} \xi_{t}^{E}\left(c_{B, t}-\delta_{B, t}\right) d t \leq 0
$$

where $\xi_{t}^{E}$ is the state price density under the econometrician's measure. The optimization in Equation (15) uses the expectation of the econometrician, indicated with the superscript $E$ in the expectation operator, $\mathbb{E}^{E}$. We multiply the period utility of $B$ at time $t$ by the ratio of probability beliefs, $\eta_{B, t}$, to get back to the expectation under the measure of $B$. Country $A$ residents face a symmetric optimization problem.

To solve for the state price density, we clear the goods market so that the sum of country outputs, $\delta_{A, t}+\delta_{B, t}$ is equal to "world consumption," $c_{W, t} \triangleq c_{A, t}+c_{B, t}$. Solving this equation for the state price density $\xi_{t}^{E}$ implies: $^{15}$

$$
\xi_{t}^{E}\left(\delta_{A, t}, \delta_{B, t}, \eta_{A, t}, \eta_{B, t}\right)=e^{-\beta t}\left[\left(\frac{\eta_{A, t}}{\lambda^{A}}\right)^{\frac{1}{1-\alpha}}+\left(\frac{\eta_{B, t}}{\lambda^{B}}\right)^{\frac{1}{1-\alpha}}\right]^{1-\alpha} c_{W, t}^{\alpha-1}
$$

where $\lambda_{A}$ and $\lambda_{B}$ are the Lagrange multipliers of the lifetime budget constraints. The state price density relative to the econometrician's measure, $\xi_{t}^{E}$, depends upon the ratios of probability measure of both countries. In fact, it is homogeneous of degree 1 in these two variables.

Proposition 4 The state price density (17) contains two priced factors: world consumption, $c_{W, t}$,

\footnotetext{
${ }^{15}$ To ease the calculation, we consider only integer levels of risk aversion so that we can expand the bracket of Equation (17) into powers. For non-integer values of risk aversion, one would need to apply an inverse Fourier transform.
} 
and world (harmonic) average foreign sentiment, given by

$$
\eta_{W, t} \triangleq\left[\left(\frac{\eta_{A, t}}{\lambda^{A}}\right)^{\frac{1}{1-\alpha}}+\left(\frac{\eta_{B, t}}{\lambda^{B}}\right)^{\frac{1}{1-\alpha}}\right]^{1-\alpha}
$$

The two priced factors are conditionally correlated. As we have seen (Equation (14)), foreign sentiment $\eta_{A}$ is perfectly correlated with the output shock of Country $B, d w_{\delta_{B}, t}^{E}$, with the sign of that correlation depending on the sign of the current disagreement $\widehat{g}_{B, t}^{A}$. Only if and when there is full agreement today $\left(\widehat{g}_{B, t}^{A}=\widehat{g}_{A, t}^{B}=0\right)$ are these correlations equal to zero. In all cases, the state price density in Equation (17) shows that, in the presence of foreign sentiment, equilibrium prices now contain additional risk premia, over and above the classic premium based on world consumption. These premia are related to the risks in individual country output shocks but not related to the risk in signal shocks, since the ratios of probability measure are not impacted by signal shocks.

In equilibrium, each country's share of world consumption is given by a monotonic transformation of the ratio of the two ratios of probability beliefs. Defining Country $A$ 's share as $\omega$, its equilibrium value is

$$
\omega\left(\frac{\eta_{A, t}}{\eta_{B, t}}\right)=\frac{\left(\frac{\lambda_{B}}{\lambda A} \frac{\eta_{A, t}}{\eta_{B, t}}\right)^{\frac{1}{1-\alpha}}}{1+\left(\frac{\lambda_{B}}{\lambda A} \frac{\eta_{A, t}}{\eta_{B, t}}\right)^{\frac{1}{1-\alpha}}}
$$

As in Dumas, Kurshev and Uppal (2009), the consumption-sharing rule is linear in world consumption $c_{W, t}$ and its slope, $\omega$. Here $\omega$ is driven by the ratio of Country $A$ beliefs to Country $B$ beliefs, $\eta_{A, t} / \eta_{B, t}$.

This relationship can be understood intuitively as follows. When the investors of Country $A$ have deemed an event more likely to occur than did investors of Country $B$, they have bet on that event through $\eta_{A, t} / \eta_{B, t}$ and, when it occurs, they get to consume more. In this way, ratios of probability beliefs act as endogenous taste shocks in each country.

In the standard case without foreign sentiment, perfect risk sharing would result in consumption growth being perfectly correlated contra empirical cross-country consumption growth correlations that 
are typically well below 1 , thereby posing a well-known puzzle. ${ }^{16}$ With foreign sentiment, however, the presence of the stochastic term $\eta_{A, t} / \eta_{B, t}$ in the sharing rule in Equation (19) means that the crosscountry conditional consumption correlation is below one all the time, except when disagreements happen to be equal to zero.

In order to obtain the portfolios of the two national groups of investors, we need to derive their total wealth processes. In doing so, we view total wealth as the price of a security with payoffs equal to optimal consumption. The wealth of the representative Country $i$ investor is

$$
W_{t}^{i}\left(\frac{\eta_{A, t}}{\eta_{B, t}}, \delta_{A, t}, \delta_{B, t}, \widehat{f}_{A, t}^{E}, \widehat{f}_{B, t}^{E}, \widehat{g}_{A, t}^{B}, \widehat{g}_{B, t}^{A}\right)=\int_{t}^{\infty} \mathbb{E}_{t}^{E}\left[\frac{\xi_{u}^{E}}{\xi_{t}^{E}} c_{i, u}\right] d u, \quad i \in\{A, B\}
$$

Since the whole mathematical framework is exponential linear quadratic (as in Cheng and Scaillet (2007)), we can obtain the conditional expectation terms and thereby the wealth, pricing functions, and their derivatives, as functions of $\left\{\widehat{f}_{A, t}^{B}, \widehat{f}_{B, t}^{B}, \widehat{g}_{A, t}^{B}, \widehat{g}_{B, t}^{A}, \frac{\delta_{B, t}}{\delta_{A, t}}, \frac{\eta_{A, t}}{\eta_{B, t}}, u-t\right\}$. The solutions for these functions are described in Appendix A and in Appendix B when outputs are uncorrelated and correlated, respectively, taking into account the fact that there are two "trees" in the world with outputs that need to be summed. We obtain the diffusion of wealth from a straightforward application of Itô's lemma. The elements of this diffusion are the target risk exposures of the investor.

To examine the aggregate equity market implications, we require a set of securities that both completes the market and makes our DOO effects most transparent. To complete the market, we need five securities with nonlinearly dependent payoffs since we have four linearly independent Brownians that are observable by investors.

Given the aggregate equity market focus of our empirical regularities, stocks that are claims to each country's output are a natural choice to make our effects transparent. Therefore, equities for country $A$ and $B$ comprise the first two securities in the menu of assets, with prices denoted $S_{A, t}$ and $S_{B, t}$, respectively. Equities are infinitely long-lived and pay amounts equal to outputs perpetually at

\footnotetext{
${ }^{16}$ For example, see the discussions in Backus, Kehoe, and Kydland (1992) and Lewis (1999).
} 
every instant. Thus, the stock price of firm $i$ is

$$
S_{i, t}\left(\frac{\eta_{A, t}}{\eta_{B, t}}, \delta_{A, t}, \delta_{B, t}, \widehat{f}_{A, t}^{E}, \widehat{f}_{B, t}^{E}, \widehat{g}_{A, t}^{B}, \widehat{g}_{B, t}^{A}\right)=\int_{t}^{\infty} \mathbb{E}_{t}^{E}\left[\frac{\xi_{u}^{E}}{\xi_{t}^{E}} \delta_{i, u}\right] d u, \quad i \in\{A, B\}
$$

We need three more securities to complete the market. For this purpose, we choose a menu of securities that allows investors to allocate their risk exposures to output shocks exclusively through country equities so that the equity preference is not polluted by indirect allocations via non equity securities. To that aim, we add three securities with payoffs that are neutral vis-à-vis output shocks. The first one is the instantaneous maturity locally riskless bond, paying the interest rate $r_{t}$. The other two are futures contracts (in zero net supply). We choose futures contracts that are marked to the fluctuations of the signal shock from each country and designed to be hedges of signal shocks only. Since the market value of a futures contract is always adjusted to be equal to zero, a zero market-value amount of capital flow is induced.

With the available menu of the two country stocks and the two futures contracts, investors must replicate the desired exposures. The $1 \times 4$ vector $\theta_{i, t}$ represents the numbers of units held by investors in Country $i$ of each available financial security:

$$
\theta_{i, t}=\left[\begin{array}{llll}
\theta_{S_{A}, t}^{i} & \theta_{S_{B}, t}^{i} & \theta_{F_{A}, t}^{i} & \theta_{F_{B}, t}^{i}
\end{array}\right], \quad i \in\{A, B\}
$$

Given the closed form solutions for the wealth of investors and the equity prices, we are able to

obtain their diffusions by Itô's lemma. Defining $x_{i, t}$ as the $1 \times 4$ diffusion vector of the wealth of Investor $i$, and $\Sigma_{t}$ as the $4 \times 4$ diffusion matrix of the four risky securities' prices, the vector $\theta_{i, t}$ can be computed directly from a system of linear equations: $x_{i, t}=\theta_{i, t} \cdot \Sigma_{t}, i \in\{A, B\}$.

\section{Quantifying the model}

As argued above, the international financial market is a natural laboratory for analyzing DOO. Therefore, we next examine the implications of DOO for various well-known empirical regularities 
using our model. In particular, we conduct a simulation under the objective probability measure (as described in Subsection 2.1). From this measure, we generate 20,000 simulated paths over 50 years with monthly time steps. Using these simulated paths, we then evaluate the ability of our model to replicate patterns similar to the empirical regularities described in the introduction. Although our model is too stylized to replicate these regularities precisely, Section 7 provides evidence using empirical proxies for disagreement that are consistent with its implications. Details of the data and simulation are explained in Appendices C and D, respectively.

\subsection{Data}

To provide an empirical reference for our model, we replicate basic findings in the literature, as described below. This analysis requires various data series, compiled to match those used in the literature. First, we follow the literature by measuring capital flows using US net foreign equity purchases data from the Department of Treasury. For robustness, we analyze three different versions of these capital flows: the raw measure of equity purchases corresponding to national income accounting, this same measure scaled by lagged foreign market capitalization as in Albuquerque, Bauer, and Schneider (2007, 2009), and the same measure scaled by lagged US investment in foreign equities as in Curcuru, Thomas, Warnock, and Wongswan (2011). To compare with this most recent study, we reconstruct the data for both sets of scaled capital flows over the time period of 1980 to $2008 .{ }^{17}$ Excess returns are calculated using the corresponding set of stock market returns from Morgan Stanley Capital International and the one-month Treasury Bill rate, all in US dollars. To provide base-line results for the international two-factor model commonly found in the literature, we also study a set of non-US companies that are listed in the US market, using the stock returns for these companies and their home market returns from Data Stream. These data are also used below to reproduce standard pricing effects around cross-listing events. We focus upon the returns for these firms because they are easily traded across international markets and, hence, are unlikely to be affected by forms of market

\footnotetext{
${ }^{17}$ Data availability over this period implies a smaller set of 13 countries for the foreign market capitalization scaling than the wider range of 42 countries for the US investment scaling. See Appendic C.1 for details.
} 
segmentation that are unrelated to DOO such as transactions costs or capital controls.

\subsection{Parameters}

Table 1 summarizes our specific parameter assumptions. Our calibrated parameters are taken from Dumas, Kurshev and Uppal (2009). They in turn chose these values based upon Brennan and Xia (2001) who considered a model of learning similar to ours but without differences of opinion. To arrive at these numbers, they considered a range of parameters for fundamentals and preferences chosen to match key features of US data. In addition, the parameter $\phi$ captures the degree to which home residents know the home signal conveys information about the conditional home output growth rate, but foreigners disregard. To highlight the potential effects of DOO, this parameter is set at level near one in the baseline model. We describe the potential impact of varying degrees of $\phi$ in our empirical Section 7 below.

To evaluate the effects of foreign sentiment risk, we calculate some basic unconditional moments for asset prices, capital flows, output and consumption produced by our model along with their data counterparts. The simulated foreign sentiment model moments for asset pricing assuming both uncorrelated output growth and a modified version with output growth correlation equal to 0.5 are reported in Panel A of Table 2. For comparison, the panel also provides the simulated model results without sentiment and those from the data. As the table shows, our foreign sentiment model delivers a stock return mean and volatility that is close to the data, though the mean and volatility of the rate of interest are too high. ${ }^{18}$ Panel B of Table 2 also reports cross-country consumption growth correlation and cross-country output growth correlation. As could be anticipated from Proposition 3, foreign sentiment lowers the unconditional consumption correlation below one, shown in Panel B. Furthermore, when $\rho=0.5$ the cross-country consumption growth correlation (equal to 0.3) is lower than cross-country output growth correlation, as observed in the data. Backus, Kehoe, and Kydland (1992) pointed out that complete-markets models have difficulty generating a higher cross-country

\footnotetext{
${ }^{18}$ The difficulty of matching the moments of the interest rate are common in DOO models such as Dumas, Kurshev and Uppal (2009).
} 
correlation in output growth than in consumption growth. Clearly, our DOO model provides an important exception due to the incorporation of foreign sentiment or belief shocks, which are effectively endogenous taste shocks making utility state dependent. These belief shocks are positively correlated across countries but are also correlated with output shocks, since each output growth provides a signal that is useful for the inference of both home and foreign fundamentals. The combination of these effects generates the observed consumption growth correlation, that is little affected by increasing output correlation.

We next consider the implications for the autocorrelation in capital flows using our base capital flow measure and that measure scaled by market capitalization. Panel $\mathrm{C}$ of Table 2, shows that these empirical autocorrelations are positive for both unscaled and scaled capital flows, with the mean and range across countries under "Data Mean" and the "Data Range", respectively. Similarly, Albuquerque, Bauer and Schneider (2007, Table 3a) estimate the autocorrelation of market capitalization-scaled capital flows for six OECD countries over an earlier period (1977:2 to 2000:3), finding a range from 0.16 to 0.52 .

Table 2 Panel $\mathrm{C}$ also reports the autocorrelation from our model for these measures. In our setup, the international capital flows -or "foreign purchases"- are interpreted as the demand of homecountry (for instance, Country $B$ ) investors for the foreign (Country $A$ ) stock valued at current market prices $S_{A, t} \times\left(\theta_{S_{A}, t}^{B}-\theta_{S_{A}, t-d t}^{B}\right)$, as in balance-of-payments accounting. ${ }^{19}$ Scaling by foreign market capitalization as in Albuquerque, Bauer, and Schneider $(2007,2009)$ produces the change in physical shares of the foreign equity, or $\theta_{S_{A}, t}^{B}-\theta_{S_{A}, t-d t}^{B}$. As Table 2 shows, this autocorrelation is negligible in our model, regardless of the measure and the degree of autocorrelation, showing that the persistence in unscaled capital flows $S_{A, t} \times\left(\theta_{S_{A}, t}^{B}-\theta_{S_{A}, t-d t}^{B}\right)$ is entirely due to the persistence in the price $S_{A, t} \cdot{ }^{20}$ Albuquerque, Bauer, and Schneider (2007) are able to generate persistence in capital flows in a model with investor heterogeneity within a country. Here, for tractability, investors are

\footnotetext{
${ }^{19}$ Recall that futures, being zero-market value securities, do not give rise to capital flows. There are flows of borrowing and lending but these would be mostly the mirror image of flows into equities.

${ }^{20}$ One insightful referee pointed out this fact.
} 
homogeneous within countries and the focus is on the heterogeneity across countries and on the role of general equilibrium pricing. In our model, the excess volatility of the endogenous rate of interest and the lack of persistence of capital flows are part and parcel of the same defect. It would be conceivable to introduce more persistence in the rate of interest and the capital flows by modifying the specification of the processes for the signals. ${ }^{21}$ That possibility will be investigated in future research.

\section{Portfolios and capital flows}

\subsection{The basic mechanism: foreign capital inflow and home return comovement}

We now turn to our first international empirical regularity: the co-movement between stock returns and capital flows. As a number of papers have documented, capital flows into countries when the stock market experiences above average returns, a phenomenon sometimes referred to as "return chasing." 22 According to the asymmetric-information model of Brennan and Cao (1997), this phenomenon occurs because foreigners' private signals are less informative about the home country's stock return than are those of the home country's residents. As public information arrives and they see home stock prices going up, less informed foreigners speculate that home investors see in the public signal a confirmation of their private signal, which must have been favorable to home stocks. Accordingly they buy the home country's stocks. In other words, the reason foreign, uninformed investors buy more of the home asset is that they update their priors regarding the quality of the home asset after positive public news about that asset. $^{23}$

In our model, the behavioral assumption is different but the logic is similar. All investors fully observe two kinds of information: current output growth and news about the future output growth

\footnotetext{
${ }^{21}$ Specifically, one could let the signal processes have a non-zero drift equal to the conditionally expected growth rates of output. This additional information about the slow-moving expected growth would cause the investors' estimates of that growth to be slower moving.

${ }^{22}$ See for example, Brennan and Cao (1997), Bohn and Tesar (1996), Grinblatt and Keloharju (2000), and Brennan, Cao, Strong and $\mathrm{Xu}(2005)$.

${ }^{23}$ We are grateful to a referee for emphasizing this interpretation.
} 
in the form of the signal. There is a difference of perception about the latter.

Figure 1 shows the basic mechanism graphically using our simulated data for our basic capital flow measure: $S_{\text {home,t }} \times\left(\theta_{\text {home,t }}^{\text {foreign }}-\theta_{\text {home,t-dt }}^{\text {foreign }}\right) \cdot{ }^{24}$ This figure plots the median capital flows and price changes conditional on the sign of home shocks. To calculate these medians, we categorize 20,000 simulated outcomes into four different groups depending upon the home shocks signs; that is, whether the output shock is positive " $\mathrm{u}$ " or negative " $\mathrm{d}$ " and the signal shock is positive " $\mathrm{u}$ " or negative " $\mathrm{d}$ ". The labels in the figure then plot the median for the specific subsample, where the first letter refers to output shock while the second letter refers to the signal shock. For example, "ud" is the median for all simulations when the output shock is positive $\left(d w_{\delta_{\mathrm{home}}, t}^{E}>0\right)$ and the signal shock is negative $\left(d w_{s_{\text {home }}, t}^{E}<0\right)$. Then to see the relationship between capital flows and price changes, suppose a positive output shock occurs at home (first label " $u$ "). All investors want to buy, driving the price up; i.e., $S_{\text {home,t }}-S_{\text {home,t-dt }}>0$. Half of the time this positive output shock is accompanied by a negative home signal (second label "d") - a fact that foreigners ignore, which leads to disagreement. In that case, home investors are willing to sell and foreigners are able to execute their buys, increasing capital inflows to home for the "ud" pair. The combination of the four label pairs clearly shows a positive relationship between capital flows and price movements, consistent with the empirical finding.

We further illustrate this relationship by simulating a standard regression found in the literature. Beginning with Brennan and Cao (1997), a number of papers have regressed net purchases of foreign equities by US investors on the foreign-market return. ${ }^{25}$ To reproduce the relationship implied by this regression, we consider two types of regression. This first type follows the relationship in Figure 1 with base capital flows. We use our simulations to regress foreign purchases by Country $B$ investors for the foreign stock valued at current market prices, $S_{A, t} \times\left(\theta_{S_{A}, t}^{B}-\theta_{S_{A}, t-d t}^{B}\right)$, on the returns of the foreign country given by the change in the stock price, $S_{A, t}-S_{A, t-d t}$. The first two columns in Panel A of Table 3, show significant regression coefficients of 0.575 and 0.734 from the model simulations

\footnotetext{
${ }^{24}$ A similar relationship holds when plotting the scaled capital flows, $\theta_{\text {home }, \mathrm{t}}^{\text {forein }}-\theta_{\text {home,t-dt }}^{\text {foreign }}$.

${ }^{25}$ See, for example, Bohn and Tesar (1997) and, more recently, Curcuru, Thomas, Warnock, and Wongswan (2011). Albuquerque, Bauer, and Schneider (2007) consider instead the correlation between capital flows and foreign market returns, finding a positive relationship.
} 
using our base capital flow measure without and with output growth correlation, respectively. ${ }^{26}$ While this regression relates capital flows to the change in stock prices, it potentially confounds the effects of stock prices on both sides so that empirical studies typically scale the capital flows with various measures. Accordingly, for our second type of regression we use scaled capital flows. Albuquerque, Bauer, and Schneider (2007) scale by foreign market capitalization, providing a particularly useful interpretation of net capital flows as the change in foreign shares, $\theta_{S_{A}, t}^{B}-\theta_{S_{A}, t-d t}^{B}$, and relate these flows to the foreign return or, in our model, $\left(S_{A, t}-S_{A, t-d t}\right) / S_{A, t-d t}$. The results of the Brennan-Cao regression coefficients for this version are reported in Table 3 Panel A in the columns labeled "Capital Flows - Scaled." 27 Similar to the results with unscaled capital flows, the Brennan-Cao coefficients increase with correlated output growth from 0.541 to 0.952 . Intuitively, when home output is high at the same time foreign output is high (which, with the positive correlation, happens more often than not), foreign investors, who ignore the home signal, ascribe a higher probability that the home conditional mean is high. Therefore, the foreign investors buy more home stocks while home residents, using the home signal, are willing to sell. As a result, an increase in home stock price is associated with even more foreign buying of the home stock than when output is uncorrelated.

Despite the increase in the coefficients with correlated output, all model implied regression coefficients are within the range in Brennan and Cao (1997) of 0.12 to 5.13. Moreover, they lie within the range of -0.02 to 1.04 using the US investment-scaled data set as well as within the range of 0.012 to 0.64 using the foreign market capitalization scaled data set. For parsimony, we report in Table 3 only the pooled regression coefficients.

As these results show, foreign sentiment generates a positive comovement between capital flows and returns. By contrast, there would be no capital flows in the absence of differences in perceptions of the news content in signals, as parameterized by $\phi$. Thus, the tendency to find a positive Brennan-Cao

\footnotetext{
${ }^{26}$ Without foreign sentiment, the capital flows would obviously be equal to zero, as in that case investors are identical and hence there is no incentive for financial trade. Accordingly, we only present results for our model with foreign sentiment.

${ }^{27}$ As an alternative, Curcuru, Thomas, Warnock, and Wongswan (2011) scale capital flows by wealth, and also decompose portfolio changes by isolating changes in flows that are not driven by portfolio rebalancing. In Appendix C.3, we replicate their empirical results and show that a similar pattern holds in our simulated model.
} 
coefficient depends upon how much the investors differ in their interpretation of the foreign signal, a relationship to which we return in Section 7 below.

\subsection{Home-equity preference}

Home-equity preference is the observation that home residents tilt their portfolios towards home equity beyond the level suggested by standard theory. ${ }^{28}$ Explanations proposed for this preference include non-tradeable goods or leisure, incomplete markets, and asymmetric information.

We next show that our foreign sentiment risk model also generates home-equity preference even though in our model all goods are tradeable, markets are fully complete, and all information is public.

The mechanism by which equity-preference is generated in the model is one reflecting intertemporal hedging and it stems from the capital-flow mechanism that we outlined in the previous section. Sitting at time $t$, an investor knows that at time $t+d t$ and thereafter he will revise his portfolio. He faces re-investment risk, which is precisely the risk that intertemporal hedging is meant to alleviate, to the extent possible. Looking at time $t+d t$ and thereafter, this sophisticated investor is aware of the correlation that we described in the previous subsection. He knows that, when it comes to foreign equity, because of his information processing handicap, he will be able to buy on the occasion of a high output shock that causes the price to be high and he will be able to sell on the occasion of a low output shock that causes the price to be low, whereas the opposite is true for domestic equity. For that reason, even though rates of return in equilibrium are symmetric between the two types of equity, he knows that he will not be able to earn as much holding and revising his holdings of foreign equity than he does doing the same with home equity. As a hedge against his handicap and as a way to forestall this unfavorable correlation, he holds less of foreign than he does of domestic equity, while still holding both for the sake of diversification. This is true as an average across states of nature (or across simulation paths).

\footnotetext{
${ }^{28}$ An extensive literature has documented this regularity. For a few examples of studies spanning several decades, see Grubel (1968), French and Poterba (1991), and more recently Ahearne, Griever and Warnock (2004). Lewis (1999, 2011) and Coeurdacier and Rey (2013) synthesize potential explanations.
} 
We use our simulated model to evaluate portfolios held by the home investor. Panels B and C of Table 3 show the median of these holdings. The columns labeled "No foreign sentiment" show that the median share invested abroad is equal to $50 \%$ without foreign sentiment risk. By contrast, the simulations including foreign sentiment risk (columns "Foreign sentiment") show a clear bias towards greater home equity holdings. The median across paths is approximately $64 \%$ for the number of home shares held in Panel C and between 57\% to $60 \%$ for the proportion of wealth held in Panel B. The table also shows that holdings of futures are small compared to equity holdings and that the volume of trading in futures is less than half the volume of trading in stocks.

\section{Pricing issues and firm-level returns}

\subsection{Two-factor consumption CAPM}

In integrated markets, risk factors are common to all securities and all securities are priced with these same factors. In our model, with no market segmentation and with all tradeable goods, equilibrium prices, such as Equation (20), are functions of seven state variables, each of which is driven by four Brownian motions that in turn can be seen as having a home or a foreign dimension. Moreover, Proposition 4 and the state price density in Equation (17) reveal that ultimately only two factors are priced: world consumption and world average foreign sentiment. The next proposition says that our model is consistent with a two-factor consumption CAPM.

Proposition 5 The following consumption-CAPM holds:

$$
\widehat{\mu}_{S_{i}}^{E}-r_{t}=(1-\alpha) \operatorname{Cov}\left(\frac{d S_{i, t}}{S_{i, t}}, \frac{d c_{W, t}}{c_{W, t}}\right)-\operatorname{Cov}\left(\frac{d S_{i, t}}{S_{i, t}}, \frac{d \eta_{W, t}}{\eta_{W, t}}\right), \quad i \in\{A, B\},
$$

where $c_{W, t}=c_{A, t}+c_{B, t}$ is world consumption and $\eta_{W, t}$ (defined in Equation (18)) is a measure of 
world average foreign sentiment risk, with dynamics given by

$$
\frac{d \eta_{W, t}}{\eta_{W, t}}=\omega\left(\frac{\eta_{A, t}}{\eta_{B, t}}\right) \frac{d \eta_{A, t}}{\eta_{A, t}}+\left[1-\omega\left(\frac{\eta_{A, t}}{\eta_{B, t}}\right)\right] \frac{d \eta_{B, t}}{\eta_{B, t}} .
$$

Proof. The market price of risk is obtained by applying Itô's Lemma to the state price density, and identifying its diffusion vector. The CAPM risk premia are derived from the market price of risk.

As in the standard consumption-based CAPM, a security risk premium is positively correlated with the covariance of its return with the world consumption growth. In our model, the risk premium is also decreasing in the covariance of the security's return with the world average foreign sentiment. The conditionally expected excess returns on the left-hand side of the CAPM relationship correspond to the way in which the econometrician would collect and process data on returns.

In empirical studies, a home risk factor often appears to be priced, in addition to a world, or foreign, factor. Our interpretation of that fact is based on Proposition 3 above, which says that the foreign sentiment risk of the investors in one country is conditionally perfectly correlated with the output shock in the other country (with the sign of the perfect correlation being opposite to the sign of current disagreement). In CAPM Equation (21), the apparent pricing of home output risk, over and above world consumption risk, derives from its correlation with world average foreign sentiment risk. The latter is the true unobserved risk factor.

\subsection{Pricing puzzle: factor model}

Much of the empirical literature on international stock returns focuses not upon a consumptionbased CAPM, but rather on the factor structure of the returns. In this literature, international firm returns appear to depend upon home factors as well as foreign or world factors, an observation often interpreted as evidence for market segmentation or non-tradeable risks. ${ }^{29}$ Moreover, the beta on the

\footnotetext{
${ }^{29}$ For studies finding home and foreign factors in returns and the related debate on the number of factors, see Agmon (1973), Lessard (1976), Heston and Rouwenhorst (1994), Cavaglia, Brightman and Aked (2000), Cavaglia and Moroz (2002), Brooks and Del Negro (2005, 2006), and Bekaert, Hodrick and Zhang (2009). For evidence that the factors are
} 
home market is typically higher than that on the foreign market.

To evaluate this relationship in our model, we now introduce a new Firm $C$ in Country $A$ with an output process similar to that of $A$ and $B$. The dynamics of Firm $C$ 's output and conditional expected output growth rate are

$$
\begin{aligned}
\frac{d \delta_{C, t}}{\delta_{C, t}} & =f_{C, t} d t+\sigma_{\delta} d z_{C, t}^{\delta}, \\
d f_{C, t} & =-\zeta\left(f_{C, t}-\bar{f}\right) d t+\sigma_{f} d z_{C, t}^{f}
\end{aligned}
$$

where $z_{C, t}^{\delta}$ and $d z_{C, t}^{f}$ are independent Brownian motions under the objective probability measure. Similarly to $A$ and $B$, investors also observe a signal about the output growth rate. Further assumptions and notational details are spelled out in Appendix E. Since firm $C$ is listed in Country $A$, investors of Country $A$ process properly the signal that is correlated with the output growth of firm $C$ while investors of Country $B$ ignore it.

With this expanded model, we examine the regression relationship of individual firm returns on home and foreign markets using our simulated data for the uncorrelated output model. ${ }^{30}$ Specifically, we regress individual Firm C's stock excess return, $\frac{d S_{C}+\delta_{C} d t}{S_{C}}-r_{t} d t$, on the corresponding Country $A$ stock excess return $\frac{d S_{A}+\delta_{A} d t}{S_{A}}-r_{t} d t$, and Country $B$ stock excess return, $\frac{d S_{B}+\delta_{B} d t}{S_{B}}-r_{t} d t .{ }^{31}$ Panel A of Table 4 shows the results of the two factor regressions on our simulated data as well as our estimates based upon the company return data. Without foreign sentiment, the symmetry assumed in our model implies foreign and home factors have the same betas. However, the difference of interpretation of signals captured by $\phi$ in our model generates foreign sentiment risk. When this risk is present, the beta on the foreign factor is smaller than the beta on the home factor, the qualitative implication of the empirical evidence. Accordingly, in Section 7 below we show empirically that the tendency for related to market segmentation, see Bekaert and Harvey (1995), among others.

${ }^{30}$ The significantly greater computational burden of adding another firm prohibits simulations for the correlated outputs case.

${ }^{31}$ The return on the stock market index of Country $A$ would normally include firm $C$. However, in our regression of $\frac{d S_{C}+\delta_{c} d t}{S_{C}}-r d t$ on the country $A$ index excess return, we exclude Firm $C$ in the index for the stock market of Country $A$, as this would bias the beta against that index. 
home and foreign betas to differ is greater for firm returns that are more sensitive to variations in the dispersion of forecaster's views.

\section{3 "Abnormal" cross-listing returns}

Cross-listing events present another feature of international security-return behavior, often associated with differing economic perceptions across countries. At the time foreign firms list in home markets, the returns on equity shares of the cross-listing firm become abnormally high relative to the market, generally between $1.5 \%$ and $7 \%$. On the other hand, the cost of capital is lowered. For example, typical estimates for the cost of capital drop after cross-listing is between $0.22 \%$ and $1.3 \%{ }^{32}$ An oft-cited explanation for these responses is that cross-listing improves information processing about the future behavior of the firm to investors in the home market. ${ }^{33}$

To evaluate this pricing behavior with our model using the motivation from the literature, we return to the three-firms extended model above. We now compare the equilibrium in which Firm $C$ is listed in Country $A$ to the equilibrium in which it is listed both in Country $A$ and in Country $B$. To capture the idea that cross-listing provides home investors with increased ability to process information about the foreign firm, we postulate that, once Firm $C$ is cross-listed, investors in Country $B$ know how to correctly interpret the public information about Firm $C$. Therefore, under crosslisting, "foreign" Country $B$ investors now recognize that the signal process conveys information about the home Firm $C$. This assumption implies that the dependence of returns on forecast disagreements will change after firms cross-list, a relationship we examine in Section 7.

Using our simulated data, we calculate average "abnormal returns" due to Firm $C$ cross listing from Country $A$ to Country $B$, as described above. Although these results simply compare the price with and without foreign sentiment risk in Firm $C$, they demonstrate the effects of removing

\footnotetext{
${ }^{32}$ On abnormal returns and the lower cost of returns, see Hail and Leuz (2009), Sarkissian and Schill (2009) and Gozzi, Levine and Schmukler (2008), for a few examples. Karolyi (2006) provides a survey.

${ }^{33}$ For example, Coffee $(1999,2002)$ argues that the cross-listing stock prices increase because these firms commit to abide by the stricter reporting standards, thereby reducing investor uncertainty. Ahearne, Griever and Warnock (2004) show that US investors are more willing to invest in firms from countries that list on US exchanges, noting that cross-listing provides information from these firms that is easier to interpret.
} 
informational uncertainty across countries, as suggested by the literature.

The results are displayed in Panel B of Table 4. Without foreign sentiment, the abnormal returns would obviously be equal to zero. With foreign sentiment, the model generates a mean percentage price increase due to cross-listing equal to $4.487 \%$ for the firm that cross-lists. This level is within the range in the literature noted above and close to our estimated price response of $3.418 \%$. Our model also generates a lower cost of capital, as in the literature. In the model, the mean reduction in the cost of capital is equal to $0.142 \%$, somewhat lower than the range of values found empirically, but similar to our estimate of $0.194 \%$. Overall, the improvement in the processing of information about a firm's growth prospects due to cross-listing affects its price quite clearly but affects its cost of capital much less, consistent with the empirical evidence mentioned above.

\section{Empirical regularities and difference of opinion proxies}

We have shown that DOO can potentially help explain several well-known international finance anomalies both qualitatively and quantitatively. Therefore, additional information might be found by looking at empirical evidence about DOO. Although directly testing our model is precluded by its highly stylized nature, we can examine indirect evidence by noting that countries presumably face varying degrees of DOO about the information content in news, captured in our model by $\phi$. For some countries and firms, opinions about the information content in news may be rather unanimous, while for others there may be more disagreement. As such, our model suggests we should find greater evidence of financial anomalies for countries and firms that are more sensitive to differences in information processing.

Therefore, in this section, we empirically investigate some relationships predicted by our model using proxies for these differences. We begin by describing these measures and relationships before turning to the results. 


\subsection{Data and Model Relationships}

To proxy for DOO about future economic activity, we use data based upon professional forecasters. We conjecture that these forecasters likely have common information so that disagreements about macroeconomic predictions result from differences of opinion. ${ }^{34}$ In the empirical analysis, we study three sets of variables. The first set is the difference between the 75 th and 25 th percentile of forecasts for US GDP and investment growth, both residential and non-residential, from the Survey of Professional Forecasters (SPF). Although these data only provide forecasts for the US, the forecasters are individuals and institutions from various countries, thereby providing a range of international views. ${ }^{35}$ A second proxy for differing opinions is the variance of the SPF individual forecasts for the four-quarter-ahead GDP growth, a variable analyzed by Bansal and Shaliastovich (2010) and Shaliastovich (2015). The third set of variables includes the "sentiment risk indices" proposed by Baker and Wurgler (2006) for the cross-section of US data and Baker, Wurgler and Yuan (2006) for global data. Unlike our other measures, these variables need not directly relate to disagreements, but we include them since they have been associated with sentiment risk in the literature. Although these various measures likely capture different effects arising from disagreements, we collectively call these measures "DOO proxies" below for simplicity.

Using these proxies, we can then ask whether relationships suggested from the model are borne out by the data. Accordingly we examine relationships based upon three of the regularities in the model. ${ }^{36}$ The first relationship is that countries with capital flows that are more sensitive to DOO have a higher Brennan-Cao coefficient. That is, as noted in Section 5, countries with greater differences in views about the information content of news arising from higher $\phi$ generate greater co-movement between capital inflows and returns. The second suggested empirical relationship is that firms with returns that are more sensitive to differing opinions have a greater difference between their home and foreign betas. We showed in Section 6.2 that differences in processing the foreign signal generated a wedge

\footnotetext{
${ }^{34}$ We are grateful to Geert Bekaert for emphasizing this point to us.

${ }^{35}$ We focus upon the US data because similar measures for other countries have an insufficient number of observations.

${ }^{36}$ We have insufficient annual observations to econometrically analyze the fourth regularity, "home-equity preference."
} 
between home and foreign betas so, conversely, firm returns that face no disagreements should have no such wedge. The third empirical relationship arises from our model conjecture in Section 6.3 that cross-listing changes the way in which the investors in the newly listed market view the cross-listed company, implying a shift in information processing. If so, the effects on firm returns due to differing views about public information should change after cross-listing. We next examine empirical evidence of these three relationships.

\subsection{Empirical Evidence}

To consider the first empirical relationship, we ask how capital flow responses would differ across countries depending upon their sensitivity to DOO proxies. For this purpose, we first establish whether proxies help explain capital flows with the following regressions: $N P_{t}^{i}=a_{0}^{i}+a_{1}^{i} D_{t}+u_{t}^{i}$, and $N P_{t}^{i}=a_{0}^{i}+a_{1}^{i} D_{t}+a_{2}^{i} R_{m t}^{i}+e_{t}^{i}$, where $N P_{t}^{i}$ are scaled U.S. net purchases of equity of country $i, D_{t}$ are the DOO proxies, and $R_{m t}^{i}$ is the market return of country $i$, all at time $t$. Studying the effects of Brennan-Cao coefficients across countries requires a cross-section of countries. Therefore, for this analysis we focus upon net purchases scaled by US holdings of foreign securities as in Curcuru, Thomas, Warnock, and Wongswan (2011) because a wider cross-section of 42 countries is available with this scaling. These initial regressions verify that the coefficients on DOO measures, $a_{1}^{i}$, are generally significantly different from zero (not reported for parsimony).

For each DOO proxy, we then sort countries into three groups based upon the absolute value of their country-specific $a_{1}$ coefficients. ${ }^{37}$ The absolute value captures the possibility that the capital inflows of some countries may be positively related to the DOO proxy while for others the capital inflows may be negatively related, but any deviation from zero generates exposure. Using these groups, we run a pooled regression of their capital inflows on their respective market returns. Panel A of Table 5 reports the coefficients on the market returns, that is, their Brennan-Cao coefficients,

\footnotetext{
${ }^{37}$ The paper reports the results for regressions with DOO proxies alone although including returns as independent variables gave similar results.
} 
where each column provides the sort on a different DOO proxy. ${ }^{38}$ Notably, the average response of capital flows to equity market return increases for countries with greater sensitivity to DOO proxies. For example, using GDP forecasts, the Brennan-Cao coefficient for the "Low $\left|\widehat{a_{1}}\right|$ " country group is only 0.005 while that of the "High $\left|\widehat{a_{1}}\right|$ " country group is 0.096. A similar pattern can be seen for almost all the other proxies. Thus, consistent with the first relationship suggested by our model, the countries with capital flows that are more sensitive to opinion dispersion are also the countries with capital flows that are more sensitive to domestic returns.

We next consider the second empirical relationship suggested by the model. Since the presence of differing opinions in our model generates a wedge between home and foreign betas, conversely, firms with no sensitivity to forecast dispersion should have no difference between these betas. To evaluate this possibility, we run initial time series CAPM regressions of the excess returns $R_{i t}$ for each of our non-US firms on the excess returns of the home and foreign (US) markets, $R_{m t}^{H o m e}$ and $R_{m t}^{U S}$, respectively, and on the DOO proxies as in: $R_{i t}=\beta_{0}+\beta_{H o m e} R_{m t}^{H o m e}+\beta_{U S} R_{m t}^{U S}+\beta_{D} D_{t}+u_{t} . \mathrm{We}$ then conduct a cross-sectional regression of $\left|\beta_{H o m e}-\beta_{U S}\right|$ on $\left|\beta_{D}\right| .{ }^{39}$ Panel B of Table 5 reports the results of this regression showing that the coefficient is indeed positive across all measures. Thus, as suggested by the model, firms with higher sensitivity to differing views about the information content in news also have higher deviations between home and foreign betas.

The third relationship from our framework is that the effects of disagreements on firm returns change after cross-listing. To estimate this change, we follow the literature by regressing the foreign company excess returns on the "Foreign" (US) market and the "Home" market and interacting these variables with a dummy after the cross-listing event. ${ }^{40}$ In other words, we run regressions of the form: $R_{i t}=b^{P R E} R_{m t}+b^{P O S T} R_{m t} I_{t}+b_{D}^{P R E} D_{t}+b_{D}^{P O S T} D_{t} I_{t}+\epsilon_{t}$, where $R_{m t}$ is the vector of Home and

\footnotetext{
${ }^{38}$ We also examined the robustness of these results along several dimensions including different time periods, using a smaller subsample of countries also studied by Curcuru, Thomas, Warnock, and Wongswan (2011), and using lagged returns as regressors, finding a similar pattern in all these cases.

${ }^{39}$ Our larger data set of over 500 firms allows this cross-sectional regression while the shorter data set of 42 countries precluded this possibility for capital flows above. Note that the standard errors from these cross-sectional regressions should be viewed with caution because they ignore the sampling error in the firm level time-series regressions.

${ }^{40}$ See, for example, Foerster and Karolyi (1999) and Sarkissian and Schill (2009). The latter paper provides a breakdown of the periods into a pre- and post-listing steady state, as in our analysis.
} 
Foreign market factors, $b^{P R E}$ and $b^{P O S T}$ are the factor loadings and $I_{t}$ is a dummy variable equal to one if the period is after cross-listing and equal to zero otherwise. In these regressions, the empirical relationship suggested by our framework would mean a change in sensitivity to DOO measures, that is: $b_{D}^{P O S T}-b_{D}^{P R E} \neq 0$.

Table 5 Panel $\mathrm{C}$ reports the estimates for the coefficients on the DOO variables. ${ }^{41}$ Given in the row labeled "Before: $b_{D}^{P R E}$ ", the coefficient estimates on $D_{t}$ prior to cross-listing are generally insignificantly different from zero. Consistent with the suggested model relationship, the row labeled "Change: $b_{D}^{P O S T}-b_{D}^{P R E}$ " indeed shows a significant change in this coefficient after cross-listing for most of the DOO variables.

\section{Conclusions}

By allowing international investors to differ in their interpretation of home and foreign public information, we showed that four regularities in international finance can be at least partially explained: (i) the co-movement of returns and international capital flows; (ii) home-equity preference; (iii) the dependence of firm returns on home and foreign factors; and (iv) abnormal returns around foreign firm cross-listing in the home market. We also analyzed how differences in forecasts relate to the regularities across countries and firms, finding evidence consistent with our model.

Overall, our model clearly demonstrates the effects of differing opinion across countries. According to that viewpoint, if someone asked: "What is a foreigner?", our answer would be: "A foreign investor is one who interprets news about home firms less correctly than home investors do." Because of this behavioral phenomenon, risk and risk premia are created over and beyond the risk of the fundamentals, by the risk that the opinions of investors living in different countries will in the future diverge from each other.

\footnotetext{
${ }^{41}$ The estimated factor loadings reflect standard findings in the literature such as an increase in betas on the US market and little or no change on the beta from the firm's home market. Therefore, they are subsumed for parsimony.
} 


\section{Appendices}

\section{A Transform analysis}

In order to obtain the prices of financial securities as well as the country wealth processes (needed for constructing the portfolios), we need to compute the expected values of the product of the change of measure with the payoffs. From the equations for the equilibrium state price density, and the expressions obtained for the stock prices and wealths, it is clear that we need the joint conditional distribution of $\left(\eta_{A, u}, \eta_{B, u}, \delta_{A, u}, \delta_{B, u}\right)^{\top}$ at some future date $u$ given the current state $\left(\eta_{A}, \eta_{B}, \delta_{A}, \delta_{B}, \widehat{f}_{A}^{E}, \widehat{f}_{B}^{E}, \widehat{g}_{A}^{B}, \widehat{g}_{B}^{A}\right)^{\top}$ at current time $t$. We can derive a moment function or Fourier trans-

form which allows us to obtain the required expressions, $\mathbb{E}_{t}^{E}\left[\left(\frac{\eta_{i, u}}{\eta_{i}}\right)^{\chi_{i}}\left(\frac{\eta_{j, u}}{\eta_{j}}\right)^{\chi_{j}}\left(\frac{\delta_{i, u}}{\delta_{i}}\right)^{\varepsilon_{i}}\left(\frac{1+\frac{\delta_{j, u}}{\delta_{i, u}}}{1+\frac{\delta_{j}}{\delta_{i}}}\right)^{\psi}\right]$ for $i \in\{A, B\}$ and $i \neq j$.

In a "one-tree" version of our economy, Dumas, Kurshev and Uppal (2009), following Yan (2008), show that, by assuming that risk aversion $1-\alpha$ is a positive integer (which can be true only when investors have risk aversion greater than or equal to 1) and using the binomial theorem, the moment function of outputs and sentiment is enough for obtaining prices and portfolios. While this property is useful in our setup, our problem is further complicated by the fact that the state price density (see Equation (17)), in our model, contains a power of the sum of two outputs: $\left(\delta_{A, t}+\delta_{B, t}\right)^{\alpha-1}$. To see why this complicates our problem, note that, since investors are risk averse, $\alpha-1<0$, the binomial theorem cannot be used to expand that term. Clearly, obtaining exact solutions for the stock prices and portfolio choice is more challenging in our "two-trees" setup.

The moment generating function in Proposition 6 contains precisely these types of elements, and can be used to obtain stock prices and wealths. 
Proposition 6 The moment generating function needed for solving stock prices and wealths is

$$
\begin{gathered}
\mathbb{E}_{t}^{E}\left[\left(\frac{\eta_{i, u}}{\eta_{i}}\right)^{\chi_{i}}\left(\frac{\eta_{j, u}}{\eta_{j}}\right)^{\chi_{j}}\left(\frac{\delta_{i, u}}{\delta_{i}}\right)^{\varepsilon_{i}}\left(\frac{1+\frac{\delta_{j, u}}{\delta_{i, u}}}{1+\frac{\delta_{j}}{\delta_{i}}}\right)^{\psi}\right]=H\left(\widehat{g}_{i}^{B}, t, u, \chi_{i}\right) \times H\left(\widehat{g}_{j}^{A}, t, u, \chi_{j}\right) \\
\times J\left(\widehat{f}_{i}^{E}, \widehat{g}_{i}^{j}, t, u, \varepsilon_{i}, \chi_{j}\right) \times G\left(\frac{\delta_{j}}{\delta_{i}}, \widehat{f}_{i}^{E}, \widehat{f}_{j}^{E}, \widehat{g}_{i}^{j}, \widehat{g}_{j}^{i}, t, u, \varepsilon_{i}, \varepsilon_{j}, \chi_{i}, \chi_{j}, \psi\right),
\end{gathered}
$$

with

$$
\begin{gathered}
H\left(\widehat{g}_{t}, t, u, \chi\right)=e^{B_{1}(t, u, \chi)+\widehat{g}_{t}^{2} B_{4}(t, u, \chi)} \\
J(\widehat{f}, \widehat{g}, t, u, \varepsilon, \chi)=e^{\varepsilon\left[K_{2}(t, u)+\widehat{f} K_{3}(t, u)+\widehat{g} B_{3}(t, u, \chi)\right]+\varepsilon\left[K_{1}(t, u)+B_{2}(t, u, \chi)\right]},
\end{gathered}
$$

and

$$
G\left(\frac{\delta_{j}}{\delta_{i}}, \widehat{f}_{i}^{E}, \widehat{f}_{j}^{E}, \widehat{g}_{i}^{j}, \widehat{g}_{j}^{i}, t, u, \varepsilon_{i}, \chi_{i}, \chi_{j}, \psi\right)=\int_{-\infty}^{+\infty}\left(1+\frac{\delta_{j}}{\delta_{i}} e^{\frac{y-\mu_{y}\left(\hat{f}_{i}^{E}, \hat{f}_{j}^{E}, \hat{g}_{i}^{j}, \hat{g}_{j}^{i}, t, u, \varepsilon_{i}, \chi_{i}, \chi_{j}\right)}{\sigma_{y}\left(t, u, \chi_{i}, \chi_{j}\right)}}\right)^{\psi} n(y) d y
$$

where

$$
\begin{aligned}
& \mu_{y}\left(\widehat{f}_{i}^{E}, \widehat{f}_{j}^{E}, \widehat{g}_{i}^{j}, \widehat{g}_{j}^{i}, t, u, \varepsilon_{i}, \chi_{i}, \chi_{j}\right)=\left(\widehat{f}_{j}^{E}-\widehat{f}_{i}^{E}\right) K_{3}(t, u)+\widehat{g}_{j}^{i} B_{3}\left(t, u, \chi_{i}\right)-\widehat{g}_{i}^{j} B_{3}\left(t, u, \chi_{j}\right) \\
&-2 \varepsilon_{i}\left[K_{1}(t, u)+B_{2}\left(t, u, \chi_{j}\right)\right], \\
& \sigma_{y}\left(t, u, \chi_{i}, \chi_{j}\right)=\sqrt{2 K_{1}(t, u)+B_{2}\left(t, u, \chi_{i}\right)+B_{2}\left(t, u, \chi_{j}\right)},
\end{aligned}
$$

and $n(\cdot)$ is a univariate standard normal density function. The functions $K_{1}, K_{2}, K_{3}, B_{1}, B_{2}, B_{3}$, and $B_{4}$ are given explicitly in the proof.

Proof. We want to compute $\mathbb{E}_{t}^{E}\left[\left(\frac{\eta_{i, u}}{\eta_{i}}\right)^{\chi_{i}}\left(\frac{\eta_{j, u}}{\eta_{j}}\right)^{\chi_{j}}\left(\frac{\delta_{i, u}}{\delta_{i}}\right)^{\varepsilon_{i}}\left(\frac{1+\frac{\delta_{j, u}}{\delta_{i, u}}}{1+\frac{\delta_{j}}{\delta_{i}}}\right)^{\psi}\right]$. Consider first obtaining a similar moment function:

$$
Z\left(\delta_{i}, \delta_{j}, \widehat{f}_{i}^{E}, \widehat{f}_{j}^{E}, \eta_{i}, \eta_{j}, \widehat{g}_{i}^{j}, \widehat{g}_{j}^{i}, t, u, \varepsilon_{i}, \varepsilon_{j}, \chi_{i}, \chi_{j}\right)=\mathbb{E}_{t}^{E}\left[\left(\frac{\eta_{i, u}}{\eta_{i}}\right)^{\chi_{i}}\left(\frac{\eta_{j, u}}{\eta_{j}}\right)^{\chi_{j}}\left(\frac{\delta_{i, u}}{\delta_{i}}\right)^{\varepsilon_{i}}\left(\frac{\delta_{j, u}}{\delta_{j}}\right)^{\varepsilon_{j}}\right]
$$


This function satisfies the following PDE:

$0 \equiv \mathcal{L} Z\left(\delta_{i}, \delta_{j}, \widehat{f}_{i}^{E}, \widehat{f}_{j}^{E}, \eta_{i}, \eta_{j}, \widehat{g}_{i}^{j}, \widehat{g}_{j}^{i}, t, u, \varepsilon_{i}, \varepsilon_{j}, \chi_{i}, \chi_{j}\right)+\frac{\partial Z}{\partial t}\left(\delta_{i}, \delta_{j}, \widehat{f}_{i}^{E}, \widehat{f}_{j}^{E}, \eta_{i}, \eta_{j}, \widehat{g}_{i}^{j}, \widehat{g}_{j}^{i}, t, u, \varepsilon_{i}, \varepsilon_{j}, \chi_{i}, \chi_{j}\right)$

with the initial condition $Z\left(\delta_{i}, \delta_{j}, \widehat{f}_{i}^{E}, \widehat{f}_{j}^{E}, \eta_{i}, \eta_{j}, \widehat{g}_{i}^{j}, \widehat{g}_{j}^{i}, t, t, \varepsilon_{i}, \varepsilon_{j}, \chi_{i}, \chi_{j}\right)=\delta_{i}^{\varepsilon_{i}} \delta_{j}^{\varepsilon_{j}} \eta_{i}^{\chi_{i}} \eta_{j}^{\chi_{j}}$, and where $\mathcal{L}$ is the differential generator of $\left(\delta_{i}, \delta_{j}, \widehat{f}_{i}^{E}, \widehat{f}_{j}^{E}, \eta_{i}, \eta_{j}, \widehat{g}_{i}^{j}, \widehat{g}_{j}^{i}\right)$ under the probability measure of the econometrician.

Because the system of state variables $\left(\delta_{i}, \delta_{j}, \widehat{f}_{i}^{E}, \widehat{f}_{j}^{E}, \eta_{i}, \eta_{j}, \widehat{g}_{i}^{j}, \widehat{g}_{j}^{i}\right)$ is in the exponential linear quadratic class, we can obtain the solution of this PDE from the solution of a simpler system of ODEs (see Cheng and Scaillet (2007)). Moreover, because of the block-diagonal structure of the diffusion matrix of the state variables (as shown in Section 2.3), we obtain the solution in closedform, as shown in the remainder of this proof.

We have

$$
\begin{aligned}
\mathbb{E}_{t}^{E}\left[\left(\frac{\eta_{i, u}}{\eta_{i}}\right)^{\chi_{i}}\left(\frac{\eta_{j, u}}{\eta_{j}}\right)^{\chi_{j}}\left(\frac{\delta_{i, u}}{\delta_{i}}\right)^{\varepsilon_{i}}\left(\frac{\delta_{j, u}}{\delta_{j}}\right)^{\varepsilon_{j}}\right] & =\mathbb{E}_{t}^{E}\left[\left(\frac{\eta_{i, u}}{\eta_{i}}\right)^{\chi_{i}}\left(\frac{\delta_{j, u}}{\delta_{j}}\right)^{\varepsilon_{j}}\right] \times \mathbb{E}_{t}^{E}\left[\left(\frac{\eta_{j, u}}{\eta_{j}}\right)^{\chi_{j}}\left(\frac{\delta_{i, u}}{\delta_{i}}\right)^{\varepsilon_{i}}\right] \\
& =Q\left(\hat{f}_{j}^{E}, \widehat{g}_{j}^{i}, t, u, \varepsilon_{j}, \chi_{i}\right) \times Q\left(\widehat{f}_{i}^{E}, \widehat{g}_{i}^{j}, t, u, \varepsilon_{i}, \chi_{j}\right) .
\end{aligned}
$$

Therefore, we can split the required moment function into the product of two separate ones, one for each subset of independent state variables. Since the dynamics of the state variables in each of these groups are similar to those in Dumas, Kurshev and Uppal (2009), and since the object is also the same as in that paper, we obtain a very similar result:

$$
Q(\widehat{f}, \widehat{g}, t, u, \varepsilon, \chi)=H_{\widehat{f}}(\widehat{f}, t, u, \varepsilon) \times H_{\widehat{g}}(\widehat{g}, t, u, \varepsilon, \chi)
$$


with

$$
\begin{aligned}
H_{\widehat{f}}(\widehat{f}, t, u, \varepsilon) & =e^{\varepsilon^{2} K_{1}(t, u)+\varepsilon\left[K_{2}(t, u)+\widehat{f} K_{3}(t, u)\right]}, \\
H_{\widehat{g}}(\widehat{g}, t, u, \varepsilon, \chi) & =e^{B_{1}(t, u, \chi)+\varepsilon^{2} B_{2}(t, u, \chi)+\varepsilon \widehat{g} B_{3}(t, u, \chi)+\widehat{g}^{2} B_{4}(t, u, \chi)},
\end{aligned}
$$

and

$$
\begin{aligned}
K_{1}(t, u)= & \left(\frac{\gamma^{E}}{\zeta}+\frac{1}{2} \sigma_{\delta}^{2}+\frac{1}{2 \zeta^{2}}\left[\left(\frac{\gamma^{E}}{\sigma_{\delta}}\right)^{2}+\left(\phi \sigma_{f}\right)^{2}\right]\right)(u-t)+\frac{1-e^{-2 \zeta(u-t)}}{4 \zeta^{3}}\left[\left(\frac{\gamma^{E}}{\sigma_{\delta}}\right)^{2}+\left(\phi \sigma_{f}\right)^{2}\right] \\
& -\frac{1-e^{-\zeta(u-t)}}{\zeta}\left(\frac{\gamma^{E}}{\zeta}+\frac{1}{\zeta^{2}}\left[\left(\frac{\gamma^{E}}{\sigma_{\delta}}\right)^{2}+\left(\phi \sigma_{f}\right)^{2}\right]\right) \\
K_{2}(t, u)= & \left(\bar{f}-\frac{1}{2} \sigma_{\delta}^{2}\right)(u-t)-\frac{1}{\zeta} \bar{f}\left[1-e^{-\zeta(u-t)}\right], \\
K_{3}(t, u)= & \frac{1}{\zeta}\left[1-e^{-\zeta(u-t)}\right] \\
B_{1}(t, u, \chi)= & \frac{a}{2} \int_{t}^{u} B_{4}(t, \tau, \chi) d \tau, \\
B_{2}(t, u, \chi)= & \int_{t}^{u} B_{3}(t, u, \chi)\left[m+n e^{-\zeta(\tau-t)}+\frac{a}{4} B_{3}(t, u, \chi)\right] d \tau, \\
B_{3}(t, u, \chi)= & \frac{\sum_{i=1}^{5} \vartheta_{i}(\chi) e^{-v_{i}(\chi)(u-t)}}{q(\chi)+b(\chi)+[q(\chi)-b(\chi)] e^{-2 q(\chi)(u-t)}}, \\
B_{4}(t, u, \chi)= & \frac{c(\chi)\left(1-e^{-2 q(\chi)(u-t)}\right)}{q(\chi)+b(\chi)+[q(\chi)-b(\chi)] e^{-2 q(\chi)(u-t)}},
\end{aligned}
$$

where

$$
\begin{array}{ll}
a=2\left[\left(\frac{\gamma^{E}-\gamma^{\times}}{\sigma_{\delta}}\right)^{2}+\left(\phi \sigma_{f}\right)^{2}\right], & l(\chi)=\chi \frac{\gamma^{E}}{\zeta} \frac{1}{\sigma_{\delta}^{2}}, \\
b(\chi)=\zeta+\frac{\gamma^{\times}}{\sigma_{\delta}^{2}}+\chi\left(\frac{\gamma^{E}-\gamma^{\times}}{\sigma_{\delta}^{2}}\right), & m=\gamma^{E}-\gamma^{\times}+\frac{\gamma^{E}}{\zeta}\left(\frac{\gamma^{E}-\gamma^{\times}}{\sigma_{\delta}^{2}}\right)+\frac{1}{\zeta}\left(\phi \sigma_{f}\right)^{2}, \\
c(\chi)=\frac{1}{2} \chi(\chi-1) \frac{1}{\sigma_{\delta}^{2}}, & n=-\frac{\gamma^{E}}{\zeta}\left(\frac{\gamma^{E}-\gamma^{\times}}{\sigma_{\delta}^{2}}\right)-\frac{1}{\zeta}\left(\phi \sigma_{f}\right)^{2}, \\
k(\chi)=-\chi\left[1+\frac{\gamma^{E}}{\zeta} \frac{1}{\sigma_{\delta}^{2}}\right], & q(\chi)=\sqrt{b(\chi)^{2}-a c(\chi),}
\end{array}
$$


and

$$
\begin{array}{ll}
v_{1}=0, & \vartheta_{1}(\chi)=\frac{2 c(\chi) m+k(\chi)[b(\chi)+q(\chi)]}{q(\chi)}, \\
v_{2}(\chi)=2 q(\chi), & \vartheta_{2}(\chi)=\frac{2 c(\chi) m+k(\chi)[b(\chi)-q(\chi)]}{q}, \\
v_{3}=\zeta, & \vartheta_{3}(\chi)=\frac{2 c(\chi) n+l(\chi)[b(\chi)+q(\chi)]}{q(\chi)-\zeta}, \\
v_{4}(\chi)=2 q(\chi)+\zeta, & \vartheta_{4}(\chi)=\frac{2 c(\chi) n+l(\chi)[b(\chi)-q(\chi)]}{q(\chi)+\zeta}, \\
v_{5}(\chi)=q(\chi), & \vartheta_{5}(\chi)=-\left[\vartheta_{1}(\chi)+\vartheta_{2}(\chi)+\vartheta_{3}(\chi)+\vartheta_{4}(\chi)\right] .
\end{array}
$$

Using this solution we can write

$$
\begin{aligned}
\mathbb{E}_{t}^{E}\left[\left(\frac{\eta_{i, u}}{\eta_{i}}\right)^{\chi_{i}}\left(\frac{\eta_{j, u}}{\eta_{j}}\right)^{\chi_{j}}\left(\frac{\delta_{i, u}}{\delta_{i}}\right)^{\varepsilon_{i}}\left(\frac{\delta_{j, u}}{\delta_{j}}\right)^{\varepsilon_{j}}\right]= & \mathbb{E}_{t}^{E}\left[e^{\chi_{j} \ln \frac{\eta_{j, u}}{\eta_{j}}+\chi_{i} \ln \frac{\eta_{i, u}}{\eta_{i}}+\varepsilon_{i} \ln \frac{\delta_{i, u}}{\delta_{i}}+\varepsilon_{j} \ln \frac{\delta_{j, u}}{\delta_{j, t}}}\right] \\
= & e^{B_{1}\left(t, u, \chi_{i}\right)+\left(\widehat{g}_{j}^{i}\right)^{2} B_{4}\left(t, u, \chi_{i}\right)} \\
& \times e^{B_{1}\left(t, u, \chi_{j}\right)+\left(\widehat{g}_{i}^{j}\right)^{2} B_{4}\left(t, u, \chi_{j}\right)} \times \Phi,
\end{aligned}
$$

where

$$
\begin{aligned}
\Phi= & e^{\varepsilon_{i}\left[K_{2}(t, u)+\widehat{f}_{i}^{E} K_{3}(t, u)+\widehat{g}_{i}^{j} B_{3}\left(t, u, \chi_{j}\right)\right]+\varepsilon_{i}^{2}\left[K_{1}(t, u)+B_{2}\left(t, u, \chi_{j}\right)\right]} \\
& \times e^{\varepsilon_{j}\left[K_{2}(t, u)+\widehat{f}_{j}^{E} K_{3}(t, u)+\widehat{g}_{j}^{i} B_{3}\left(t, u, \chi_{i}\right)\right]+\varepsilon_{j}^{2}\left[K_{1}(t, u)+B_{2}\left(t, u, \chi_{i}\right)\right]}
\end{aligned}
$$

corresponds to the moment function of a bivariate normal distribution:

$$
\left(\begin{array}{c}
\ln \frac{\delta_{i, u}}{\delta_{i}} \\
\ln \frac{\delta_{j, u}}{\delta_{j}}
\end{array}\right) \sim N\left(\mu_{\delta}\left(\widehat{f}_{i}^{E}, \widehat{f}_{j}^{E}, \widehat{g}_{i}^{j}, \widehat{g}_{j}^{i}, t, u, \varepsilon_{i}, \chi_{i}, \chi_{j}\right), \Sigma_{\delta}\left(t, u, \chi_{i}, \chi_{j}\right)\right)
$$

with

$$
\begin{gathered}
\mu_{\delta}\left(\widehat{f}_{i}^{E}, \widehat{f}_{j}^{E}, \widehat{g}_{i}^{j}, \widehat{g}_{j}^{i}, t, u, \varepsilon_{i}, \chi_{i}, \chi_{j}\right)=\left[\begin{array}{cc}
K_{2}(t, u)+\widehat{f}_{i}^{E} K_{3}(t, u)+\widehat{g}_{i}^{j} B_{3}\left(t, u, \chi_{j}\right) \\
K_{2}(t, u)+\widehat{f}_{j}^{E} K_{3}(t, u)+\widehat{g}_{j}^{i} B_{3}\left(t, u, \chi_{i}\right)
\end{array}\right], \\
\Sigma_{\delta}\left(t, u, \chi_{i}, \chi_{j}\right)=\left[\begin{array}{cc}
2\left[K_{1}(t, u)+B_{2}\left(t, u, \chi_{j}\right)\right] & 0 \\
0 & 2\left[K_{1}(t, u)+B_{2}\left(t, u, \chi_{i}\right)\right]
\end{array}\right]
\end{gathered}
$$


From properties of normal distributions, it follows that $\Phi$ also corresponds to this alternative bivariate normal distribution:

$$
\left(\begin{array}{c}
\ln \frac{\delta_{i, u}}{\delta_{i}} \\
\ln \frac{\delta_{j, u}}{\delta}-\ln \frac{\delta_{i, u}}{\delta_{i}}
\end{array}\right) \sim N\left(\widetilde{\mu}_{\delta}\left(\widehat{f}_{i}^{E}, \widehat{f}_{j}^{E}, \widehat{g}_{i}^{j}, \widehat{g}_{j}^{i}, t, u, \varepsilon_{i}, \chi_{i}, \chi_{j}\right), \widetilde{\Sigma}_{\delta}\left(t, u, \chi_{i}, \chi_{j}\right)\right)
$$

where

$$
\begin{gathered}
\widetilde{\mu}_{\delta}\left(\widehat{f}_{i}^{E}, \widehat{f}_{j}^{E}, \widehat{g}_{i}^{j}, \widehat{g}_{j}^{i}, t, u, \varepsilon_{i}, \chi_{i}, \chi_{j}\right)=\left[\begin{array}{c}
K_{2}(t, u)+\widehat{f}_{i}^{E} K_{3}(t, u)+\widehat{g}_{i}^{j} B_{3}\left(t, u, \chi_{j}\right) \\
\left(\widehat{f}_{j}^{E}-\widehat{f}_{i}^{E}\right) K_{3}(t, u)+\widehat{g}_{j}^{i} B_{3}\left(t, u, \chi_{i}\right)-\widehat{g}_{i}^{j} B_{3}\left(t, u, \chi_{j}\right)
\end{array}\right], \\
\widetilde{\Sigma}_{\delta}\left(t, u, \chi_{i}, \chi_{j}\right)=\left[\begin{array}{cc}
2\left[K_{1}(t, u)+B_{2}\left(t, u, \chi_{j}\right)\right] & -2\left[K_{1}(t, u)+B_{2}\left(t, u, \chi_{j}\right)\right] \\
-2\left[K_{1}(t, u)+B_{2}\left(t, u, \chi_{j}\right)\right] & 4 K_{1}(t, u)+2\left[B_{2}\left(t, u, \chi_{i}\right)+B_{2}\left(t, u, \chi_{j}\right)\right]
\end{array}\right] .
\end{gathered}
$$

Therefore, we obtain that the moment function given in Proposition 6 is equivalent to

$$
\begin{aligned}
& \mathbb{E}_{t}^{E}\left[\left(\frac{\eta_{i, u}}{\eta_{i}}\right)^{\chi_{i}}\left(\frac{\eta_{j, u}}{\eta_{j}}\right)^{\chi_{j}}\left(\frac{\delta_{i, u}}{\delta_{i}}\right)^{\varepsilon_{i}}\left(\frac{\delta_{j, u}}{\delta_{i, u}} / \frac{\delta_{j}}{\delta_{i}}\right)^{v}\right] \\
= & \mathbb{E}_{t}^{E}\left[e^{\left.\chi_{j} \ln \frac{\eta_{j, u}}{\eta_{j}}+\chi_{i} \ln \frac{\eta_{i, u}}{\eta_{i}}+\varepsilon_{i} \ln \frac{\delta_{i, u}}{\delta_{i}}+v \ln \left(\frac{\delta_{j, u}}{\delta_{j}}-\ln \frac{\delta_{i, u}}{\delta_{i}}\right)\right]}\right. \\
= & H\left(\widehat{g}_{i}^{B}, t, u, \chi_{i}\right) \times H\left(\widehat{g}_{j}^{A}, t, u, \chi_{j}\right) \times J\left(\widehat{f}_{i}^{E}, \widehat{g}_{i}^{j}, t, u, \varepsilon_{i}, \chi_{j}\right) \\
& \times e^{\nu\left[\mu_{y}\left(\widehat{f}_{i}^{E}, \widehat{f}_{j}^{E}, \widehat{g}_{i}^{j}, \widehat{g}_{j}^{i}, t, u, \varepsilon_{i}, \chi_{i}, \chi_{j}\right)\right]+\nu^{2} \sigma_{y}^{2}\left(t, u, \chi_{i}, \chi_{j}\right)},
\end{aligned}
$$

where the functions $H, J, \mu_{y}$ and $\sigma_{y}^{2}$ are given in the proposition.

In order to use this moment function to compute the required expectation, we integrate over the log output ratio conditional normal distribution, which is implicit in this moment function. 


\section{B Introducing output correlation}

In this section we show how to solve our model when outputs are correlated across countries. To introduce output correlation symmetrically, we posit that the stochastic process for $\delta_{i, t}(i \in\{A, B\})$ is

$$
\frac{d \delta_{i, t}}{\delta_{i, t}}=f_{i, t} d t+\sigma_{\delta}\left(\sqrt{\frac{1+\sqrt{1-\rho^{2}}}{2}} d z_{i, t}^{\delta}+\sqrt{\frac{1-\sqrt{1-\rho^{2}}}{2}} d z_{j, t}^{\delta}\right), i \neq j ; i, j \in\{A, B\}
$$

where $z_{i}^{\delta}$ are independent Brownian motions under the objective probability measure, which governs empirical realizations of the process. The dynamics of the conditional growth rates $f_{i, t}$ of outputs and of the signals under the true measure remain exactly the same as in Equations (2) and (3), respectively.

Applying filtering under these assumptions, the conditional mean of the growth rate of output in Country $i$ as estimated by the econometrician, $\widehat{f}_{i, t}^{E}$, has dynamics

$$
d \widehat{f}_{i, t}^{E}=\zeta\left(\bar{f}-\widehat{f}_{i, t}^{E}\right) d t+\frac{\gamma^{E}-\rho \widetilde{\gamma}^{E}}{\sigma_{\delta}\left(1-\rho^{2}\right)} d w_{\delta_{i}, t}^{E}+\frac{\widetilde{\gamma}^{E}-\rho \gamma^{E}}{\sigma_{\delta}\left(1-\rho^{2}\right)} d w_{\delta_{j}, t}^{E}+\phi \sigma_{f} d w_{s_{i}, t}^{E}
$$

where $\widetilde{\gamma}^{E}$ is the steady-state covariance of $\widehat{f}_{A}^{E}-f_{A}$ and $\widehat{f}_{B}^{E}-f_{B}$, while $\gamma^{E}$ is the steady-state variance of $\widehat{f}_{A}^{E}-f_{A}$ and it is also the steady-state variance of $\widehat{f}_{B}^{E}-f_{B}$, these variances being equal to each other by virtue of symmetry:

$$
\begin{aligned}
& \widetilde{\gamma}^{E} \triangleq \sigma_{\delta}^{2}\left(\sqrt{\frac{\zeta^{2}\left(1+\rho^{2}\right)+\left(1-\phi^{2}\right) \frac{\sigma_{f}^{2}}{\sigma_{\delta}^{2}}-\sqrt{\left(1-\rho^{2}\right)\left(\zeta^{4}\left(1-\rho^{2}\right)+2 \zeta^{2}\left(1-\phi^{2}\right) \frac{\sigma_{f}^{2}}{\sigma_{\delta}^{2}}+\left(1-\phi^{2}\right)^{2} \frac{\sigma_{f}^{4}}{\sigma_{\delta}^{4}}\right)}}{2}}\right. \\
&\times \operatorname{Sign}(\rho)-\rho \zeta) \\
& \gamma^{E} \triangleq \sigma_{\delta}^{2}\left(\sqrt{\left(1-\rho^{2}\right)\left(\zeta^{2}\left(1-\rho^{2}\right)+\left(1-\phi^{2}\right) \frac{\sigma_{f}^{2}}{\sigma_{\delta}^{2}}-\frac{\left(\widetilde{\gamma}^{E}\right)^{2}}{\sigma_{\delta}^{4}}-2 \zeta \rho \frac{\widetilde{\gamma}^{E}}{\sigma_{\delta}^{2}}\right)}-\zeta\left(1-\rho^{2}\right)\right)+\rho \widetilde{\gamma}^{E} .
\end{aligned}
$$


We can then write the dynamics of the output processes under the measure of the econometrician:

$$
\frac{d \delta_{i, t}}{\delta_{i, t}}=\widehat{f}_{i, t}^{E} d t+\sigma_{\delta}\left(\sqrt{\frac{1+\sqrt{1-\rho^{2}}}{2}} d w_{\delta_{i}, t}^{E}+\sqrt{\frac{1-\sqrt{1-\rho^{2}}}{2}} d w_{\delta_{j}, t}^{E}\right) ; \quad i \neq j ; \quad i, j \in\{A, B\}
$$

The investors' interpretation of the signals is exactly the same as the one described in Section 2.3. Defining $\widehat{f}_{j}^{i}$ as the conditional mean of the output growth in Country $j$ as estimated by investors in Country $i$, we obtain

$$
\begin{aligned}
& d \widehat{f}_{i, t}^{i}=\zeta\left(\bar{f}-\widehat{f}_{i, t}^{i}\right) d t+\frac{\gamma^{X}-\rho \widetilde{\gamma}}{\sigma_{\delta}^{2}\left(1-\rho^{2}\right)}\left(\frac{d \delta_{i, t}}{\delta_{i, t}}-\widehat{f}_{i, t}^{i} d t\right)+\frac{\widetilde{\gamma}-\rho \gamma^{X}}{\sigma_{\delta}^{2}\left(1-\rho^{2}\right)}\left(\frac{d \delta_{j, t}}{\delta_{j, t}}-\widehat{f}_{j, t}^{i} d t\right)+\phi \sigma_{f} d s_{i, t}, \\
& d \widehat{f}_{j, t}^{i}=\zeta\left(\bar{f}-\widehat{f}_{j, t}^{i}\right) d t+\frac{\widetilde{\gamma}-\rho \gamma^{Y}}{\sigma_{\delta}^{2}\left(1-\rho^{2}\right)}\left(\frac{d \delta_{i, t}}{\delta_{i, t}}-\widehat{f}_{i, t}^{i} d t\right)+\frac{\gamma^{Y}-\rho \widetilde{\gamma}}{\sigma_{\delta}^{2}\left(1-\rho^{2}\right)}\left(\frac{d \delta_{j, t}}{\delta_{j, t}}-\widehat{f}_{j, t}^{i} d t\right),
\end{aligned}
$$

where $\gamma^{X}$ is the steady-state variance of $\widehat{f}_{i, t}^{i}-f_{i}, \gamma^{Y}$ is the steady-state variance of $\widehat{f}_{j, t}^{i}-f_{j}$, and $\widetilde{\gamma}$ is their covariance:

$$
\begin{aligned}
& \widetilde{\gamma} \triangleq \rho \sigma_{\delta}^{2}\left(\sqrt{\frac{\left\{\zeta^{2}\left[2\left(1+\rho^{2}\right)\left(1-\phi^{2}\right)+\phi^{4}\right]+\left(2-3 \phi^{2}+\phi^{4}\right) \frac{\sigma_{f}^{2}}{\sigma_{\delta}^{2}}\right.}{\left.-2\left(1-\phi^{2}\right) \sqrt{\left(1-\rho^{2}\right)\left(\zeta^{4}\left(1-\rho^{2}\right)+\zeta^{2}\left(2-\phi^{2}\right) \frac{\sigma_{f}^{2}}{\sigma_{\delta}^{2}}+\left(1-\phi^{2}\right) \frac{\sigma_{f}^{4}}{\sigma_{\delta}^{4}}\right)}\right\}}-\zeta},\right. \\
& \gamma^{X} \triangleq \sigma_{\delta}^{2}\left(\sqrt{\left(1-\rho^{2}\right)\left(\zeta^{2}\left(1-\rho^{2}\right)+\left(1-\phi^{2}\right) \frac{\sigma_{f}^{2}}{\sigma_{\delta}^{2}}-\frac{\widetilde{\gamma}^{2}}{\sigma_{\delta}^{4}}-2 \zeta \rho \frac{\widetilde{\gamma}}{\sigma_{\delta}^{2}}\right)}-\zeta\left(1-\rho^{2}\right)\right)+\rho \widetilde{\gamma} \\
& \gamma^{Y}=\left.\gamma^{X}\right|_{\phi=0}=\sigma_{\delta}^{2}\left(\sqrt{\left(1-\rho^{2}\right)\left(\zeta^{2}\left(1-\rho^{2}\right)+\frac{\sigma_{f}^{2}}{\sigma_{\delta}^{2}}-\frac{\widetilde{\gamma}^{2}}{\sigma_{\delta}^{4}}-2 \zeta \rho \frac{\widetilde{\gamma}}{\sigma_{\delta}^{2}}\right)}-\zeta\left(1-\rho^{2}\right)\right)+\rho \widetilde{\gamma}
\end{aligned}
$$


As in the text, the "disagreements" between the econometrician and the investors are defined as:

$$
\widehat{g}_{i}^{j} \equiv \widehat{f}_{i, t}^{E}-\widehat{f}_{i, t}^{j} ; i, j \in\{A, B\}
$$

With output correlation, investors disagree with the econometrician about the estimate of the conditional growth rate of their own output, because the behavioral bias in their estimate of the foreign output growth rate forecast spills over into the home output growth rate forecast. Therefore, $\widehat{g}_{i}^{j}$ stands for two pairs of disagreements for each country's investor, with dynamics

$$
\begin{aligned}
& d \widehat{g}_{i, t}^{i}=-\left[\frac{\sqrt{1+\sqrt{1-\rho^{2}}}\left(\widetilde{\gamma}-\rho \gamma^{X}\right)-\sqrt{1-\sqrt{1-\rho^{2}}}\left(\gamma^{X}-\rho \widetilde{\gamma}\right)}{\sqrt{2} \sigma_{\delta}^{2}\left(1-\rho^{2}\right)^{\frac{3}{2}}} \widehat{g}_{j, t}^{i}\right. \\
& \left.+\left(\zeta+\frac{\sqrt{1+\sqrt{1-\rho^{2}}}\left(\gamma^{X}-\rho \widetilde{\gamma}\right)-\sqrt{1-\sqrt{1-\rho^{2}}}\left(\widetilde{\gamma}-\rho \gamma^{X}\right)}{\sqrt{2} \sigma_{\delta}^{2}\left(1-\rho^{2}\right)^{\frac{3}{2}}}\right) \widehat{g}_{i, t}^{i}\right] d t \\
& +\frac{\left(\widetilde{\gamma}^{E}-\widetilde{\gamma}\right)-\rho\left(\gamma^{E}-\gamma^{X}\right)}{\sigma_{\delta}\left(1-\rho^{2}\right)} d w_{\delta_{j}, t}^{E}+\frac{\left(\gamma^{E}-\gamma^{X}\right)-\rho\left(\widetilde{\gamma}^{E}-\widetilde{\gamma}\right)}{\sigma_{\delta}\left(1-\rho^{2}\right)} d w_{\delta_{i}, t}^{E}, \\
& d \widehat{g}_{j, t}^{i}=-\left[\frac{\sqrt{1+\sqrt{1-\rho^{2}}}\left(\widetilde{\gamma}-\rho \gamma^{Y}\right)-\sqrt{1-\sqrt{1-\rho^{2}}}\left(\gamma^{Y}-\rho \widetilde{\gamma}\right)}{\sqrt{2} \sigma_{\delta}^{2}\left(1-\rho^{2}\right)^{\frac{3}{2}}} \widehat{g}_{i, t}^{i}\right. \\
& \left.+\left(\zeta+\frac{\sqrt{1+\sqrt{1-\rho^{2}}}\left(\gamma^{Y}-\rho \widetilde{\gamma}\right)-\sqrt{1-\sqrt{1-\rho^{2}}}\left(\widetilde{\gamma}-\rho \gamma^{Y}\right)}{\sqrt{2} \sigma_{\delta}^{2}\left(1-\rho^{2}\right)^{\frac{3}{2}}}\right) \widehat{g}_{j, t}^{i}\right] d t \\
& +\frac{\left(\widetilde{\gamma}^{E}-\widetilde{\gamma}\right)-\rho\left(\gamma^{E}-\gamma^{Y}\right)}{\sigma_{\delta}\left(1-\rho^{2}\right)} d w_{\delta_{j}, t}^{E}+\frac{\left(\gamma^{E}-\gamma^{Y}\right)-\rho\left(\widetilde{\gamma}^{E}-\widetilde{\gamma}\right)}{\sigma_{\delta}\left(1-\rho^{2}\right)} d w_{\delta_{i}, t}^{E}+\phi \sigma_{f} d w_{s_{i}, t}^{E},
\end{aligned}
$$

where $i \neq j ; \quad i, j \in\{A, B\}$.

The changes from the probability measure of the econometrician to those of investors in Country 
$A$ and $B$ are then

$$
\begin{aligned}
& \frac{d \eta_{A, t}}{\eta_{A, t}}=-\frac{\sqrt{1+\sqrt{1-\rho^{2}}} \widehat{g}_{A, t}^{A}-\sqrt{1-\sqrt{1-\rho^{2}}} \widehat{g}_{B, t}^{A}}{\sigma_{\delta} \sqrt{2\left(1-\rho^{2}\right)}} d w_{\delta_{A}, t}^{E} \\
& -\frac{\sqrt{1+\sqrt{1-\rho^{2}}} \widehat{g}_{B, t}^{A}-\sqrt{1-\sqrt{1-\rho^{2}}} \widehat{g}_{A, t}^{A}}{\sigma_{\delta} \sqrt{2\left(1-\rho^{2}\right)}} d w_{\delta_{B}, t}^{E}, \\
& \frac{d \eta_{B, t}}{\eta_{B, t}}=-\frac{\sqrt{1+\sqrt{1-\rho^{2}}} \widehat{g}_{A, t}^{B}-\sqrt{1-\sqrt{1-\rho^{2}}} \widehat{g}_{B, t}^{B}}{\sigma_{\delta} \sqrt{2\left(1-\rho^{2}\right)}} d w_{\delta_{A}, t}^{E} \\
& -\frac{\sqrt{1+\sqrt{1-\rho^{2}}} \widehat{g}_{B, t}^{B}-\sqrt{1-\sqrt{1-\rho^{2}}} \widehat{g}_{A, t}^{B}}{\sigma_{\delta} \sqrt{2\left(1-\rho^{2}\right)}} d w_{\delta_{B}, t}^{E} .
\end{aligned}
$$

In order to obtain the prices of financial securities as well as the country wealth processes (needed for constructing the portfolios), we need the joint conditional distribution of $\left(\eta_{A, u}, \eta_{B, u}, \delta_{A, u}, \delta_{B, u}\right)^{\top}$ at some future date $u$ given the current state $\left(\eta_{A}, \eta_{B}, \delta_{A}, \delta_{B}, \widehat{f}_{A}^{E}, \widehat{f}_{B}^{E}, \widehat{g}_{A}^{B}, \widehat{g}_{B}^{B}, \widehat{g}_{A}^{A}, \widehat{g}_{B}^{A}\right)^{\top}$ at current time t. As shown in Appendix A (see in particular the proof of Proposition 6), we can obtain the prices of financial securities as well as the country wealth processes from the following moment function:

$Z\left(\delta_{i}, \delta_{j}, \widehat{f}_{i}^{E}, \widehat{f}_{j}^{E}, \eta_{i}, \eta_{j}, \widehat{g}_{i}^{j}, \widehat{g}_{j}^{j}, \widehat{g}_{i}^{i}, \widehat{g}_{j}^{i}, t, u, \varepsilon_{i}, \varepsilon_{j}, \chi_{i}, \chi_{j}\right)=\mathbb{E}_{t}^{E}\left[\left(\frac{\eta_{i, u}}{\eta_{i}}\right)^{\chi_{i}}\left(\frac{\eta_{j, u}}{\eta_{j}}\right)^{\chi_{j}}\left(\frac{\delta_{i, u}}{\delta_{i}}\right)^{\varepsilon_{i}}\left(\frac{\delta_{j, u}}{\delta_{j}}\right)^{\varepsilon_{j}}\right]$

This function satisfies the following PDE:

$$
\begin{aligned}
0 \equiv & \mathcal{L} Z\left(\delta_{i}, \delta_{j}, \widehat{f}_{i}^{E}, \widehat{f}_{j}^{E}, \eta_{i}, \eta_{j}, \widehat{g}_{i}^{j}, \widehat{g}_{j}^{j}, \widehat{g}_{i}^{i}, \widehat{g}_{j}^{i}, t, u, \varepsilon_{i}, \varepsilon_{j}, \chi_{i}, \chi_{j}\right) \\
& +\frac{\partial Z}{\partial t}\left(\delta_{i}, \delta_{j}, \widehat{f}_{i}^{E}, \widehat{f}_{j}^{E}, \eta_{i}, \eta_{j}, \widehat{g}_{i}^{j}, \widehat{g}_{j}^{j}, \widehat{g}_{i}^{i}, \widehat{g}_{j}^{i}, t, u, \varepsilon_{i}, \varepsilon_{j}, \chi_{i}, \chi_{j}\right) .
\end{aligned}
$$

with the initial condition $Z\left(\delta_{i}, \delta_{j}, \widehat{f}_{i}^{E}, \widehat{f}_{j}^{E}, \eta_{i}, \eta_{j}, \widehat{g}_{i}^{j}, \widehat{g}_{j}^{j}, \widehat{g}_{i}^{i}, \widehat{g}_{j}^{i} t, t, \varepsilon_{i}, \varepsilon_{j}, \chi_{i}, \chi_{j}\right)=\delta_{i}^{\varepsilon_{i}} \delta_{j}^{\varepsilon_{j}} \eta_{i}^{\chi_{i}} \eta_{j}^{\chi_{j}}$, and where $\mathcal{L}$ is the differential generator of $\left(\delta_{i}, \delta_{j}, \widehat{f}_{i}^{E}, \widehat{f}_{j}^{E}, \eta_{i}, \eta_{j}, \widehat{g}_{i}^{j}, \widehat{g}_{j}^{j}, \widehat{g}_{i}^{i}, \widehat{g}_{j}^{i}\right)$ under the probability measure of the econometrician. 
Because the system of state variables $\left(\delta_{i}, \delta_{j}, \widehat{f}_{i}^{E}, \widehat{f}_{j}^{E}, \eta_{i}, \eta_{j}, \widehat{g}_{i}^{j}, \widehat{g}_{j}^{j}, \widehat{g}_{i}^{i}, \widehat{g}_{j}^{i}\right)$ is in the exponential linear quadratic class, we can obtain the solution of this PDE from the solution of a simpler system of ODEs (see Cheng and Scaillet (2007)). With output correlations, however, the diffusion matrix of the state variables does not have a block diagonal structure, and the solution of the system of ODEs, while in principle available in closed form, becomes complicated and is more quickly obtained numerically. Our solution is still explicit, and it is exact up to the numerical solution of a Riccati system of ODEs, which can be obtained at arbitrarily high precision in Mathematica.

\section{Data Description}

In this appendix we describe the data employed in the text. These data are used for two purposes: (a) to provide the summary measures of empirical regularities for the simulated model in Sections 4, 5 , and 6 ; and (b) to consider how those regularities relate to various market disagreement proxies in Section 7 .

\section{C.1 Summary Measures for Model Comparison}

The means and standard deviations of the asset pricing moments in Panel A of Table 2 are calculated using the same aggregate US market equity return and US Treasury bill data over the same time period as recent capital flow analysis in the literature, described below. In particular, equity is the Morgan Stanley Capital International Total Return Index for the U.S., and the interest rate is the one-month T-bill rate from Data Stream, both series from 1980 to 2008.

The capital flow data used to estimate the autocorrelations and regressions in, respectively, Panel C of Table 2 and Panel A of Table 3 are from the U.S. Treasury data base. We consider three different versions of capital flows: (a) U.S. net purchases of foreign equities; (b) U.S. net equity purchases scaled by beginning of period foreign market capitalization as in Albuquerque, Bauer, and Schneider (2007, 2009), and (c) U.S. net equity purchases scaled by beginning of period holdings of foreign securities by U.S. investors following Curcuru, Thomas, Warnock, and Wongswan (2011). For analysis with set 
(b), we use the six non-US countries considered by Albuquerque, Bauer, and Schneider (2007) along with another seven countries for which we have a full set of net equity purchases and foreign market capitalization over the full period. Scaling the data in this way provides capital flows from the following thirteen countries: Austria, Australia, Canada, Switzerland, Germany, Denmark, France, Great Britain, Italy, Japan, the Netherlands, Singapore, and South Africa. For the set (c) results, we use the 42 countries in Curcuru, Thomas, Warnock, and Wongswan (2011). These monthly measures of net equity purchases combine low frequency positions from security-level surveys with higher frequency flow data. The set of countries for this scaling is: Argentina, Australia, Austria, Belgium, Brazil, Canada, Chile, Columbia, Czech Republic, Denmark. Finland, France. Germany, Great Britain, Greece, Hong Kong, Hungary, India, Indonesia, Ireland, Israel, Italy, Japan, Korea, Malaysia, Mexico, Netherlands, Norway, Pakistan, Peru, Philippines, Poland, Portugal, Russia, Singapore, South Africa, Spain, Sweden, Switzerland, Taiwan, Thailand, and Turkey. Much of the general results in the paper were also estimated using the smaller 20 country set analyzed by Curcuru, Thomas, Warnock and Wongswan (2011) yielding similar results.

The Brennan-Cao regressions in Panel A of Table 3 and Section 7 also require market returns for each country. For this purpose, we construct a data set of foreign returns using Morgan Stanley Capital International Total Return Indices for the country markets, all measured in US dollars. To be consistent with the main findings of the more recent Curcuru, Thomas, Warnock, and Wongswan (2011) study, these data are analyzed over the period 1980 to 2008.

The foreign stock returns analyzed in the two-factor CAPM regressions in Panel A of Table 4 and the cross-listing statistics in Panel B of Table 4 are the set of foreign company returns traded on US exchanges. In order to provide returns with sufficient liquidity as well as time series data, we chose the set of foreign companies traded in the US by 2004 on the NYSE or NASDAQ, a filter that provides 576 potential firms. ${ }^{42}$ The returns were calculated from the Data Stream International Total Return Indices in US dollars for each of these firms as well as for their home markets. For the

\footnotetext{
${ }^{42}$ Specifically, these foreign stocks are traded either as American Depositary Receipts or are directly listed on the exchanges as in the case of Canadian companies.
} 
analysis based upon pre- and post-cross-listing, we dropped firms with fewer than 52 observations before cross-listing, resulting in 311 firms for that analysis. The constituent companies and their cross-listing dates were obtained from the three custodian banks for the ADRs and from Doidge, Karolyi, and Stulz (2004) for the Canadian firms. To provide a standard benchmark using the DOO measures described below, we conducted our firm level analysis from 1980 to the beginning of 2010, when the US Sentiment Index data ends.

\section{C.2 Difference of Opinion Measures}

In Section 7, we considered the relationship between some regularities and various DOO measures used in the literature. The first two sets are calculated from the Survey of Professional Forecasters (SPF) database. The other set of measures are the Sentiment Risk Indices based upon the first principal components of a number of variables considered to capture US investor sentiment by Baker and Wurgler (2006) and global investor sentiment by Baker, Wurgler, and Yuan (2012). For each of these variables, we use the data over the available time period, although their frequencies vary. The U.S. sentiment indices are monthly and available through 2010. However, the Global Sentiment Index is annual and ends in 2005. For this proxy, therefore, we generate a monthly series using the annual sentiment data following the steps in $\mathrm{Yu}(2013)$.

\section{C.3 Active Portfolio Reallocation Measures}

The positive coefficients on foreign returns from capital flow regressions have been called "return chasing" by Bohn and Tesar (1997), among others. However, Curcuru, Thomas, Warnock and Wongswan (2011) note that this positive relationship may simply reflect a passive increase in the value of foreign assets when their returns increase. They address this possibility by isolating the change in the portfolio allocation in foreign equities that result from active changes in share holdings, an approach also taken by Hau and Rey (2008). When they regress these active portfolio reallocations on returns, they find on-average much lower coefficients that are generally insignificant from zero. To investigate this 
possibility, we calculate the "active portfolio reallocations" specified in Curcuru, Thomas, Warnock and Wongswan (2011) as ${ }^{43}$

$$
\text { Active Portfolio Reallocations }=\frac{S_{A, t} \times \theta_{S_{A}, t}^{B}}{S_{A, t} \times \theta_{S_{A}, t}^{B}+S_{B, t} \times \theta_{S_{B}, t}^{B}}-\frac{S_{A, t} \times \theta_{S_{A}, t-d t}^{B}}{S_{A, t} \times \theta_{S_{A}, t-d t}^{B}+S_{B, t} \times \theta_{S_{B}, t-d t}^{B}} \text {. }
$$

Thus, the active reallocation is the change in the value of foreign portfolio shares owned by Country $B$ investors, due to changes in equity holdings and not in prices.

To determine whether our model captures the relationship found by Curcuru, Thomas, Warnock and Wongswan (2011), we simulate this variable in the uncorrelated and correlated output growth versions of our model. We find that the coefficient on Active Portfolio Reallocations is closer to zero than the corresponding coefficient on foreign returns alone, for both correlated and uncorrelated output models. This finding reflects a more muted relationship between active portfolio reallocation and returns, than for total foreign purchases, consistent with the Curcuru, Thomas, Warnock and Wongswan (2011) results. Moreover, the coefficients on Active Portfolio Reallocations are not significantly different from zero as in Curcuru, Thomas, Warnock and Wongswan (2011). Overall, therefore, our highly stylized model is remarkably consistent with two co-occurring findings in the literature about capital flows - a positive Brennan-Cao coefficient and little-to-no response in Active Portfolio Reallocations.

\section{Non-stationarity and simulation}

Stationarity. Existing studies on the survival of irrational traders ask whether excessively pessimistic or optimistic agents survive in the long run in an economy in which one population of agents knows the true probability distribution. These studies include Kogan, Ross, Wang and Westerfield (2006), Yan (2008) and Dumas, Kurshev and Uppal (2009). These studies conclude that, although "irrational" traders do not survive in the long-run, they disappear very slowly, in terms of consumption shares.

\footnotetext{
${ }^{43} \mathrm{CTWW}$ only consider the share of equities as a proportion of foreign equities. In our two country model, we use the same concept to consider foreign equities as a proportion of all equities, in this case home and abroad.
} 
In our model, both types of investors are symmetrically underconfident about the foreign signals. It is not obvious ex-ante, therefore, whether the equilibrium we have obtained is stationary or not.

To throw some light on the issue, we obtain, as in Dumas, Kurshev and Uppal (2009), the probability distribution of the future Country $A$ 's consumption share $\left(\omega_{u}\right)$ under the objective probability measure, by Fourier Inversion of the characteristic function of the ratio of foreign sentiments $\frac{\eta_{A}}{\eta_{B}}$. Figure 2 plots the probability density function of $\omega_{u}$ for different initial values $\omega_{t}$. The left panel displays the case in which Country $A$ 's consumption share is currently smaller $\left(\omega_{t}=0.25\right)$ and the right panel displays the case in which both countries's consumption shares are currently the same $\left(\omega_{t}=0.5\right)$. We see from this figure that, independently of the current relative consumption shares, as time passes, the probability distribution expands to the edges, exhibiting non-stationarity of the consumption shares. But it does so rather slowly.

Details of the simulation analysis. Using monthly time steps, we perform an exact simulation of the state variables $\left(\delta_{A}, \delta_{B}, \widehat{f}_{A}^{E}, \widehat{f}_{B}^{E}, \widehat{g}_{A}^{B}, \widehat{g}_{B}^{A}\right)$ for which exact transition probability distributions are known. For variables $\left(\eta_{A}, \eta_{B}\right)$, we rely on a simple Euler-Maruyama discretization. We sometimes get outlier paths. Prompted by a referee, we have verified that these are legitimate observations and not the result of simulation errors. To confirm that, we have gradually reduced the time step of the simulation (down from one year to $1 / 32$ of a year) and observed no change in the histograms of any of the state variables. We have also found no systematic increase or decrease in the Min or the Max of any of them. The referee provided the rationale for these outliers being actually part of the solution: "Consider the process for disagreement described in Equation (12). The public shock decreases disagreement because $\gamma^{\times}>\gamma^{E}$. But a high $\gamma^{\times}$also increases mean reversion in disagreement accelerating the decrease in disagreement. Therefore, periods of high disagreement that are followed by output news that everyone follows, may look like outliers."

Although these paths occur very rarely, statistics calculated across paths that involve portfolio choices are sensitive to them. For that reason, we resort to robust statistics whenever portfolio choices are involved. This choice is also made, for example, by Beeler and Campbell (2012). 
While the simulation is conducted under the objective probability measure (as in Subsection 2.1), the comparison of simulated data with empirical results remains a delicate exercise because of the non-stationarity of our model. As a way of alleviating the problem created by the non-stationarity of our model, we take several precautions. First, to obtain moments that are as little dependent on initial conditions as possible, or to approach unconditional moments, we run the simulations over as long a span of time as we can afford. We chose $T=50$ years (600 monthly observations). ${ }^{44}$ Second, we draw many paths, namely 20,000 paths. Third, we split these 20,000 paths into five subsamples, and use different sets of initial values for the state variables in each subsample. Fourth, we compute moments across paths at the terminal points of the simulation. Moments calculated across paths are valid representations of the behavior of the model, whether or not the model is stationary.

We verify that the frequency distribution of the consumption share obtained from the simulation for the 50-year horizon closely matches the theoretical probability distribution shown in Figure 2.

We are careful to impose symmetry between the two markets $A$ and $B .{ }^{45}$ And, when we introduce the third firm $C$, we run the simulation in such a way that $A$ and $B$ remain symmetric in their joint relationship with $C$. In this way, we have a clean no-foreign-sentiment benchmark when we examine the empirical regularities.

\section{E A cross section}

As indicated in the text, let there be one firm listed in Country $B$, which we call Firm $B$, and let there be two firms listed in Country $A$, which we call Firm $A$ and Firm $C$. Under the objective probability measure, the outputs of Firms $A$ and $B$ are as they were before but we now introduce the output of the new Firm $C$ as

$$
\frac{d \delta_{C, t}}{\delta_{C, t}}=f_{C, t} d t+\sigma_{\delta} d z_{C, t}^{\delta}
$$

\footnotetext{
${ }^{44}$ Although we run the model over 50 years, the economic agents in our simulation have an infinite horizon, not a 50-year horizon.

${ }^{45}$ For more precision in the means and medians, we have also used the technique of antithetic variates.
} 
where $z_{C, t}^{\delta}$ is an independent Brownian motion under the objective probability measure, which governs empirical realizations of the process.

The conditional expected growth rate $f_{C, t}$ of output is also stochastic:

$$
d f_{C, t}=\zeta\left(\bar{f}-f_{C, t}\right) d t+\sigma_{f} d z_{C, t}^{f}
$$

As before, all investors must estimate, or filter out, the current value of $f_{i, t}$ and its future behavior. They do so by observing the current cash flows and the three public signals $\left(s_{A}, s_{B}, s_{C}\right)$ The signal correlated with $d z_{C, t}^{f}$ evolves according to

$$
d s_{C, t}=\phi d z_{C, t}^{f}+\sqrt{1-\phi^{2}} d z_{C, t}^{s}
$$

where $z_{C}^{s}$ is a Brownian motion, under the objective probability measure as well. All the Brownian motions are independent from each other.

Investors in Country $A$ (where firms $A$ and $C$ are listed) perform their filtering under the belief that the signals $s_{A}$ and $s_{C}$ have the correct correlation with $f_{A}$ and $f_{C}$; but they believe incorrectly that the signal $s_{B}$ has zero correlation with $f_{B}$, which means that they ignore the information about the firms listed in the other country. The "model" they have in mind for this signal, in addition to those for the signal processes of $A$ and $B$ in Equation (7), posits that the dynamics of the signal process of $C$ are those given in Equation (22).

Investors in Country $B$ (where Firm $B$ is listed) perform their filtering under the belief that the signal $s_{B}$ has the correct correlation with $f_{B}$; but they believe incorrectly that the signals $s_{A}$ and $s_{C}$ have zero correlation with $f_{A}$ and $f_{C}$, which means that they ignore the information about the firms listed in the other country. The "model" they have in mind, in addition to those for the signal 
processes of $A$ and $B$ in Equation (8), posits that

$$
d s_{C, t}=d z_{C, t}^{s}
$$

By following exactly the same steps as in Section 2, we can show that the vector of exogenous state variables under the reference measure of the econometrician is given by the Markovian system comprised of Equations (4), (6), (12) and (14), to which we now add the following three analogous equations for Firm $C$ 's output, expected conditional growth rate, and disagreement, respectively:

$$
\begin{aligned}
\frac{d \delta_{C, t}}{\delta_{C, t}} & =\widehat{f}_{C, t}^{E} d t+\sigma_{\delta} d w_{\delta_{C}, t}^{E}, \\
d \widehat{f}_{C, t}^{E} & =\zeta\left(\bar{f}-\widehat{f}_{C, t}^{E}\right) d t+\frac{\gamma^{E}}{\sigma_{\delta}} d w_{\delta_{C}, t}^{E}+\phi \sigma_{f} d w_{s_{C}, t}^{E}, \\
d \widehat{g}_{C, t}^{B} & =-\left(\zeta+\frac{\gamma^{\times}}{\sigma_{\delta}^{2}}\right) \widehat{g}_{C, t}^{B} d t+\frac{\gamma^{\times}-\gamma^{E}}{\sigma_{\delta}} d w_{\delta_{C}, t}^{E}+\phi \sigma_{f} d w_{s_{C}, t}^{E},
\end{aligned}
$$

and the new change from the measure of investor $B$ to that of the econometrician $\widetilde{\eta}_{B, t}$ :

$$
\frac{d \widetilde{\eta}_{B, t}}{\widetilde{\eta}_{B, t}}=-\frac{1}{\sigma_{\delta}}\left(\widehat{g}_{A, t}^{B} d w_{\delta_{A}, t}^{E}+\widehat{g}_{C, t}^{B} d w_{\delta_{C}, t}^{E}\right)
$$

Therefore, we get an extended vector of ten exogenous state variables which drive the economy: $\tilde{Y}_{t} \equiv\left(\delta_{A, t}, \widehat{f}_{A, t}^{E}, \widehat{g}_{A, t}^{B}, \eta_{B, t}, \delta_{B, t}, \widehat{f}_{B, t}^{E}, \widehat{g}_{B, t}^{A}, \eta_{A, t}, \delta_{c, t}, \widehat{f}_{c, t}^{E}, \widehat{g}_{C, t}^{B}, \eta_{C, t}\right)^{\top}$ where $\eta_{C}$ is defined as:

$$
\frac{d \eta_{C, t}}{\eta_{C, t}}=-\frac{1}{\sigma_{\delta}} \widehat{g}_{C, t}^{B} d w_{\delta_{C}, t}^{E}
$$

so that $\widetilde{\eta}_{B, t}=\eta_{B, t} \times \eta_{C, t}$. The structure is very similar to that of our two-firm model of Section 2 . 
But there is now a third system $Y_{C, t}$ where

$$
Y_{C, t}=\left\{\delta_{C, t}, \widehat{f}_{C, t}^{E}, \widehat{g}_{C, t}^{B}, \eta_{C, t}\right\}^{T}
$$

Therefore this system can be written as

$$
d Y_{C, t}=\mu_{C, t} d t+\Omega_{C, t} d w_{C, t}^{E}
$$

where

$$
d w_{C, t}^{E}=\left\{d w_{\delta_{C}, t}^{E}, d w_{s_{C}, t}^{E}\right\}
$$

and

$$
\Omega_{C, t}=\left[\begin{array}{cc}
\sigma_{\delta} \delta_{i, t} & 0 \\
\left(\frac{\gamma^{E}}{\sigma_{\delta}}\right) & \phi \sigma_{f} \\
\left(\frac{\gamma^{E}-\gamma^{\times}}{\sigma_{\delta}}\right) & \phi \sigma_{f} \\
-\eta_{C, t}\left(\frac{\widehat{g}_{C, t}^{B}}{\sigma_{\delta}}\right) & 0
\end{array}\right] .
$$

Thus, the state vector can be evaluated as three independent sets of processes. For instance, the full vector of twelve state variables $\widetilde{Y}_{t}$ can be written as

$$
d \tilde{Y}_{t}=\widetilde{\mu}_{t} d t+\tilde{\Omega}_{t} d \vec{w}_{i, t}^{E}
$$

where

$$
d \vec{w}_{i, t}^{E}=\left\{d w_{\delta_{A}, t}^{E}, d w_{\delta_{B}, t}^{E}, d w_{\delta_{C}, t}^{E}, d w_{s_{A}, t}^{E}, d w_{s_{B}, t}^{E}, d w_{s_{C}, t}^{E}\right\}
$$

and

$$
\tilde{\Omega}_{t}=\left[\begin{array}{ccc}
\Omega_{A, t} & 0 & 0 \\
0 & \Omega_{B, t} & 0 \\
0 & 0 & \Omega_{C, t}
\end{array}\right]
$$


where $\tilde{\Omega}_{t}$ is still block diagonal, a property we exploit again in seeking the equilibrium in this extended model.

In this setting we now have six different Brownian motions. Hence we need seven linearly independent securities in order to complete the market. Since we intend to replicate a regression of a firm stock excess return on a home country stock excess return and a foreign country stock excess return, we choose our menu of securities accordingly. In particular we consider three stocks: (i) a stock $S_{C}$ which is a claim on the output of Firm $C\left(\delta_{C}\right)$; (ii) a stock $S_{A, C}$ which is a claim on the output of Firm $A$, taken to represent the equity market of Country $A\left(\delta_{A}\right)$; and (iii) a stock $S_{B}$ which is a claim on the foreign output $\delta_{B}$. As in Section 3, we complete the market with a locally riskless, instantaneously maturing bond deposit and three zero-net supply futures contracts whose prices are marked to the fluctuations of the three signal shocks, and are designed to hedge these shocks only. 


\section{REFERENCES}

Acemoglu D., V. Chernozhukov and M. Yildi, 2015, "Fragility of asymptotic agreement under bayesian learning," forthcoming in Theoretical Economics.

Albuquerque R., G. Bauer and M. Schneider, 2007, "International equity flows and returns: A quantitative equilibrium approach," Review of Economic Studies, 74, 1-30.

Albuquerque R., G. Bauer and M. Schneider, 2009, "Global private information in international equity markets," Journal of Financial Economics, 94, 18-46.

Agmon T., 1973, "Country risk: The significance of the country factor for the share price movements in the United Kingdom, Germany and Japan," Journal of Business, 46, 24-32.

Ahearne A., W. Griever and F. Warnock, 2004, "Information costs and home bias: An analysis of US holdings of foreign equities," Journal of International Economics, 62, 313-336.

Avramov, D., G. Kaplanski and H. Levy, 2015, "Talking numbers: Technical versus fundamental recommendations," working paper, The Hebrew University of Jerusalem and Bar-Ilan University.

Backus, D., P. Kehoe and F. Kydland, 1992, "International real business cycles," Journal of Political Economy, 101, 473-484.

Baker, M. and J. Wurgler, 2006, "Investor sentiment and the cross-section of stock returns," Journal of Finance, 51, 1645-1680.

Baker, M., J. Wurgler and Y. Yuan, 2012, "Global, local, and contagious investor sentiment," Journal of Financial Economics, 104, 272-287.

Bamber L., O. Barron and T. Stober, 1999, "Differential interpretations and trading volume," Journal of Financial and Quantitative Analysis, 34, 369-386.

Bansal R. and I. Shalisatovich, 2010, "Confidence risk and asset prices," American Economic Review, 100, 537-541. 
Beeler J. and J. Campbell, 2012, "The long-run risks model and aggregate asset prices: an empirical assessment," Critical Finance Review, 1, 141-182.

Bekaert G. and C. Harvey, 1995, "Time-varying world market integration," Journal of Finance, $50,403-444$.

Bekaert G., R. Hodrick and X. Zhang, 2009, "International stock return comovements," Journal of Finance, 64, 2591-2626.

Bohn H. and L. Tesar, 1996, "U.S. Equity investment in foreign markets: Portfolio rebalancing or return chasing?," American Economic Review, 86, 77-81.

Brennan M. and H. Cao, 1997, "International portfolio investment flows," Journal of Finance, 52, $1851-1880$.

Brennan M., H. Cao, N. Strong and X. Xu, 2005, "The dynamics of international equity market expectations", Journal of Financial Economics, 77, 257-288.

Brennan, M. and Y. Xia, 2001, "Stock price volatility and equity premium," Journal of Monetary Economics, 47, 249-283.

Brooks R. and M. Del Negro, 2005, "A latent factor model with global, country, and industry shocks for international stock returns," IMF Working Paper \# 05/52.

Brooks R. and M. Del Negro, 2006, "Firm-level evidence on international stock market comovement," The Review of Finance, 10, 69-98.

Cao H. and H. Ou-Yang, 2008, "Differences of opinion of public information and speculative trading in stocks and options," Review of Financial Studies, 22, 299-335.

Cavaglia S., C. Brightman and M. Aked, 2000, "The increasing importance of industry factors," Financial Analysts Journal, 56, 41-54.

Cavaglia S. and V. Moroz, 2002, "Cross-industry, cross-country allocation," Financial Analysts Journal, 58, 78-98. 
Cecchetti S., P. Lam and N. Mark, 2000, "Asset pricing with distorted beliefs: Are equity returns too good to be true?," American Economic Review, 90, 787-805.

Cheng P. and O. Scaillet, 2007, "Linear-quadratic jump-diffusion modelling," Mathematical Finance, $17,575-598$.

Cochrane J., F. Longstaff and P. Santa Clara, 2008, "Two trees," Review of Financial Studies, $21,347-385$.

Coeurdacier N. and H. Rey, 2013, "Home bias in open economy financial macroeconomics," Journal of Economic Literature, 51, 63-115.

Coffee J., 1999, "The future as history: the prospects for global convergence in corporate governance and its implications," Northwestern University Law Review, 93, 641-708.

Coffee J., 2002, "Racing towards the top? The impact of cross-listings and stock market competition on international corporate governance," Columbia Law Review, 102, 1757-1831.

Collin-Dufresne, P., M. Johannes and L. Lochstoer, 2015, "Parameter learning in general equilibrium: the asset pricing implications," forthcoming in American Economic Review.

Curcuru S., C. Thomas, F. Warnock and J. Wongswan, 2011, "US international equity investment and past and prospective returns," American Economic Review 101, 3440-3455.

Doidge, C., A. Karolyi and R. Stulz, 2004, "Why are foreign firms listed in the U.S. worth more?," Journal of Financial Economics, 71, 205-238.

Doskeland, T. and H. Hvide, 2011, "Do individual investors have asymmetric information based on work experience?," Journal of Finance, 66, 1011-1041.

Dovern, J., U. Fritsche and J. Slacalek, 2012, "Disagreement among forecasters in G7 countries." Review of Economics and Statistics 94, 1081-1096

Dumas B., A. Kurshev and R. Uppal, 2009, "Equilibrium portfolio strategies in the presence of sentiment risk and excess volatility," Journal of Finance, 64, $579-629$. 
Dvořák T., 2003, "Gross capital flows and asymmetric information," Journal of International Money and Finance, 22, 835-864.

Foerster, S. and A. Karolyi, 1999, "The effects of market segmentation and investor recognition on asset prices: Evidence from foreign stocks listings in the United States," Journal of Finance, 54, 981-1013.

Forbes, K. and F. Warnock, 2011, "Capital flow waves: Surges, stops, flight, and retrenchment," NBER Working Paper \# 17351

French K. and J. Poterba, 1991, "Investor diversification and international equity markets," American Economic Review, 81, 222-226.

Gehrig T., 1993, "An information based explanation of the domestic bias in international equity investment," Scandinavian Journal of Economics, 95, 97-109.

Gozzi J., R. Levine and S. Schmukler, 2008, "Internationalization and the evolution of corporate valuation," Journal of Financial Economics, 88, 607-632.

Grinblatt M. and M. Keloharju, 2000, "The investment behavior and performance of various investor types: A study of Finland's unique data set," Journal of Financial Economics, 55, 43-67.

Grubel H., 1968, "Internationally diversified portfolios," American Economic Review, 58, 12951314.

Hail L. and C. Leuz, 2009, "Cost of capital effects and changes in growth expectations around U.S. cross-listings," Journal of Financial Economics, 93, 428-454.

Harris M., and A. Raviv, 1993, "Differences of opinion make a horse race," Review of Financial Studies, 6, 473-506.

Hatchondo J., 2008, "Asymmetric information and the lack of portfolio diversification," International Economic Review, 49, 1297-1330. 
Hatchondo J., P. Krusell and M. Schneider, 2014, "Asset trading and valuation with uncertain exposure," working paper, Federal Reserve Bank of Richmond, Stockholm University and Stanford University.

Hau H. and H. Rey, 2008, "Global portfolio rebalancing under the microscope," working paper, University of Geneva and London Business School.

Jia C., Y. Wang and W. Xiong, 2015, "Social trust and differential reactions of local and foreign investors to public news," NBER working paper \# 21075.

Heston S. and G. Rouwenhorst, 1994, "Does industrial structure explain the benefits of international diversification?," Journal of Financial Economics, 36, 3-27.

Kandel E., and N. Pearson, 1995, "Differential interpretation of public signals and trade in speculative markets," Journal of Political Economy, 103, 831-872.

Karolyi G., 2006, "The world of cross-listings and cross-listings of the world: Challenging conventional wisdom," Review of Finance, 10, 99-152.

Kim O. and R. Verrecchia, 1991, "Trading volume and price reactions to public announcements," Journal of Accounting Research, 29, 302-321.

Kogan L., S. Ross, J. Wang and M. Westerfield, 2006, "The price impact and survival of irrational traders," Journal of Finance, 61, 195-229.

Lehavy R. and R. Sloan, 2008, "Investor recognition and stock returns," Review of Accounting Studies, 13, 327-361.

Lessard D., 1976, "World, country, and industry relationships in equity returns," Financial Analysts Journal, 32, 32-38.

Lewis K., 1999, "Trying to explain home bias in equities and consumption," Journal of Economic Literature, 37, 571-608.

Lewis K., 2011, "Global asset pricing," Annual Review of Financial Economics, 3, 435-466. 
Lipster R. and A. Shiryaev, 2000, Statistics and Random Processes II: Applications, Berlin: Springer-Verlag.

Loewenstein M. and G. Willard, 2006, "The limits of investor behavior," Journal of Finance, 61, $231-258$.

Martin, I., 2013, "The Lucas orchard," Econometrica, 81, 55-111.

Merton R., 1987, "A simple model of capital market equilibrium with incomplete information," Journal of Finance, 42, 483-510.

Morris S., 1995, "The common prior assumption in economic theory," Economics and Philosophy, $11,227-253$.

Osambela, E., 2015, "Differences of opinion, endogenous liquidity, and asset prices," Review of Financial Studies, 28, 1914-1959.

Patton, A. and A. Timmermann, "Why do forecasters disagree? Lessons from the term structure of cross-sectional dispersion," Journal of Monetary Economics, 57, 803-820.

Richardson S., R. Sloan and H. You, 2012, "What makes stock prices move? Fundamentals vs. Investor recognition," Financial Analyst Journal, 68, 30-50.

Rubinstein A., 1993, "On price recognition and computational complexity in a monopolistic model," Journal of Political Economy, 101, 473-484.

Sarkissian S. and M. Schill, 2009, "Are there permanent valuation gains to overseas listing?," Review of Financial Studies, 22, 371-412.

Scheinkman J. and W. Xiong, 2003, "Overconfidence and speculative bubbles," Journal of Political Economy, 111, 1183-1219.

Shaliastovich I., 2015, "Learning, confidence, and option prices," Journal of Econometrics, 187, 18-42. 
Singleton K., 2014, "Investor flows and the 2008 Boom/Bust in oil prices," Management Science, $60,300-318$.

Van Nieuwerburgh S. and L. Veldkamp, 2009, "Information acquisition and under-diversification," Review of Economic Studies, 77, 779-805.

Wang, J., 1994, "A model of competitive stock trading volume," Journal of Political Economy, $102,127-168$.

Xiong W. and H. Yan, 2010, "Heterogeneous expectations and bond markets," Review of Financial Studies, 23, 1433-1466.

Yan H., 2008, "Natural selection in financial markets: Does it work?," Management Science, 54, $1935-1950$.

Yu, J., 2013, "A Sentiment-based explanation of the forward premium puzzle," Journal of Monetary Economics, 60, 474-491. 


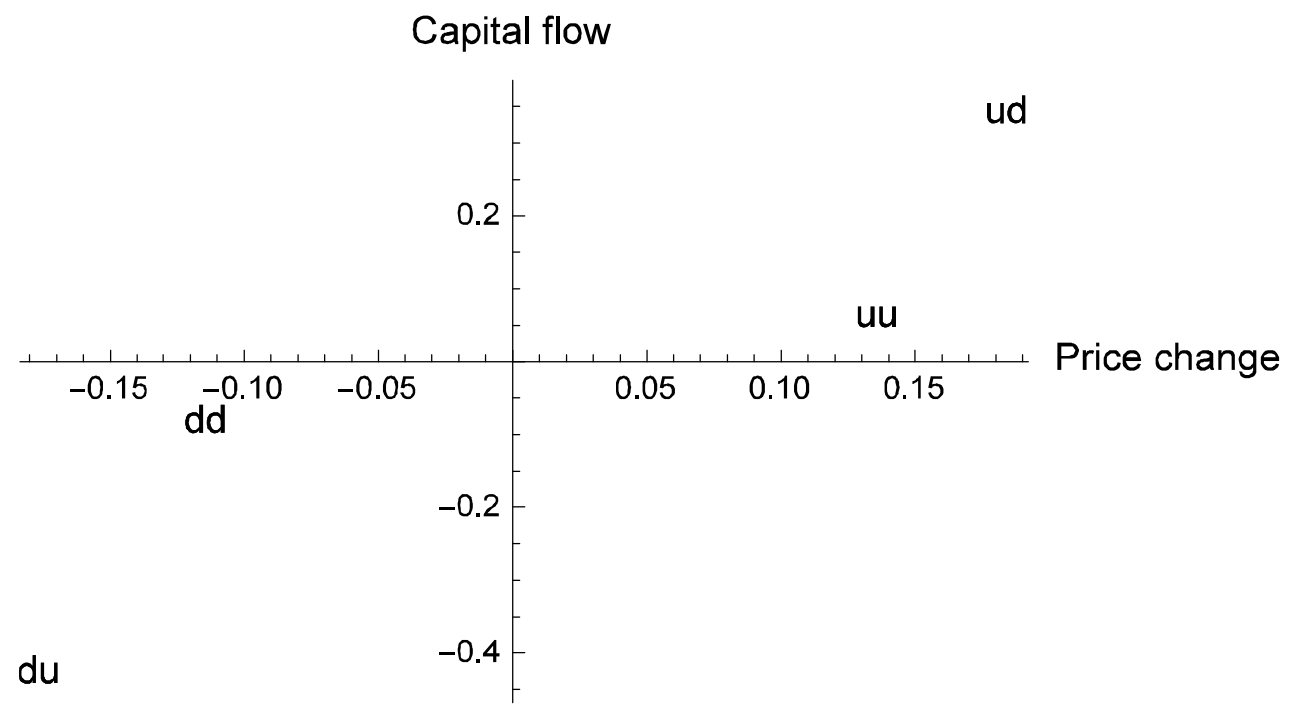

Figure 1: Conditional medians of home-equity price change and foreign capital inflows. This figure plots the median home-equity price change and foreign capital inflows conditional on the sign of home shocks. The first letter refers to output shock while the second letter refers to the signal shock. "u" refers to a positive shocks and "d" refers to a negative shock. The conditional medians are calculated across 20,000 paths at $t=50$ years. 

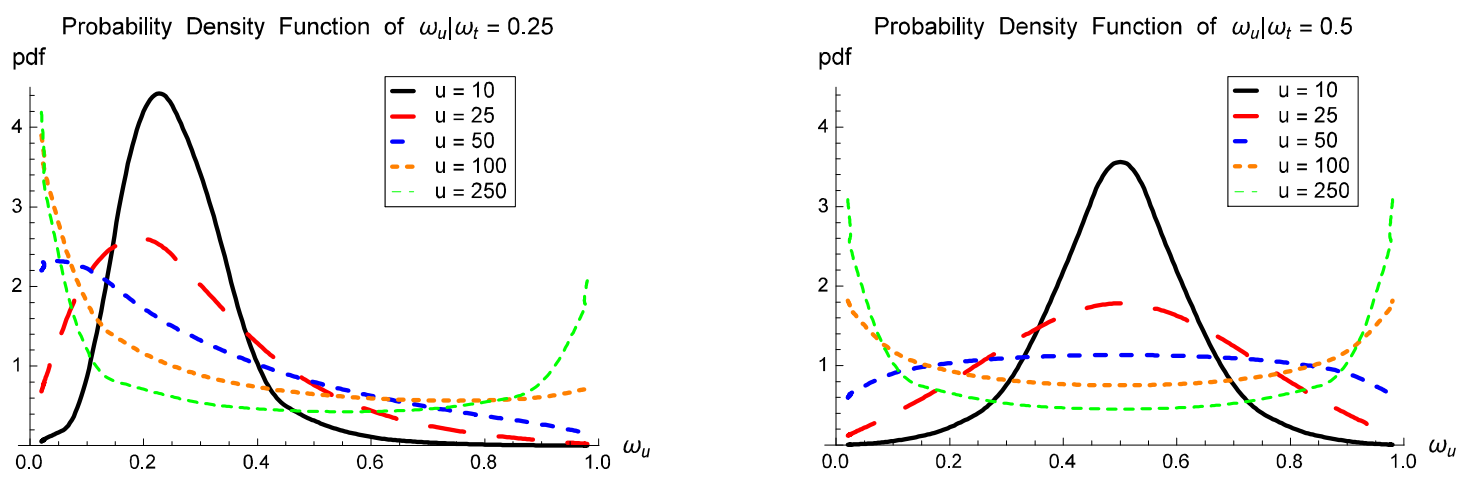

Figure 2: Non stationarity of the equilibrium. Left panel: probability density function of the consumption share for various horizons (in years) for an intial share equal to $\omega_{t}=0.25$. Right panel: the same for an initial share $\omega_{t}=0.5$. 
Table 1: Parameters. This table lists the parameter values used for all the (other) tables and figures in the paper. These values are taken from Dumas, Kurshev and Uppal (2009).

\begin{tabular}{lll}
\hline \hline Name & Symbol Value \\
\hline Parameters for output dynamics & & \\
& & \\
& $\bar{f}$ & 0.015 \\
Long-term average growth rate of output & $\sigma_{f}$ & 0.03 \\
Volatility of expected growth rate of output & $\sigma_{\delta}$ & 0.13 \\
Volatility of output & $\rho$ & $0,0.5$ \\
Output correlation & $\zeta$ & 0.2 \\
Mean reversion parameter & & \\
& & \\
Parameters for investors' preferences and beliefs & $\beta$ & 0.1 \\
& & $1-\alpha$ \\
Subjective discount rate & $\phi$ & 0.95 \\
Relative risk aversion & & 0 \\
True correlation between foreign signal and mean foreign growth rate & - & \\
Perceived correlation between foreign signal and mean foreign growth rate & $\frac{\lambda_{B}}{\lambda_{A}}$ & 1 \\
Relative Lagrange multipliers of the lifetime budget constraints & & \\
\hline \hline
\end{tabular}


Table 2: Moments. This table reports selected moments in the benchmark model with and without foreign sentiment, with and without cross-country correlation $(\rho=0.5$ and $\rho=0$, respectively), and in the data. Panel A provides the means and standard deviations of the interest rate and stock return. Panel B reports the cross-country correlations of consumption and output growth. Panel C gives estimates of the autocorrelation in foreign equity purchases, using robust least squares (MM estimation) for the model. P-values for the coefficient being different from zero are in the parentheses.

\begin{tabular}{|c|c|c|c|c|c|}
\hline \multicolumn{6}{|c|}{ Panel A: Asset pricing moments (annualized percentages) } \\
\hline \multirow[t]{2}{*}{ Moment } & \multirow{2}{*}{\multicolumn{2}{|c|}{$\begin{array}{l}\text { No foreign sentiment } \\
(\rho=0) \quad(\rho=0.5)\end{array}$}} & \multicolumn{2}{|c|}{ Foreign sentiment } & \multirow[t]{2}{*}{ Data } \\
\hline & & & $(\rho=0)$ & $(\rho=0.5)$ & \\
\hline Interest rate mean & 7.62 & 6.35 & 9.77 & 9.35 & 5.43 \\
\hline Interest rate standard deviation & 10.79 & 10.69 & 7.13 & 8.03 & 0.88 \\
\hline Stock return mean & 11.58 & 10.92 & 11.21 & 11.43 & 11.40 \\
\hline Stock return standard deviation & 21.79 & 22.53 & 15.08 & 16.75 & 15.25 \\
\hline \multicolumn{6}{|c|}{ Panel B: Macroeconomic moments } \\
\hline Moment & \multirow{2}{*}{\multicolumn{2}{|c|}{$\begin{array}{l}\text { No foreign sentiment } \\
(\rho=0) \quad(\rho=0.5)\end{array}$}} & \multicolumn{2}{|c|}{ Foreign sentiment } & Data \\
\hline & & & $(\rho=0)$ & $(\rho=0.5)$ & \\
\hline Consumption growth correlation & 1.00 & 1.00 & 0.29 & 0.30 & 0.28 \\
\hline Output growth correlation & 0.00 & 0.50 & 0.00 & 0.50 & 0.44 \\
\hline \multicolumn{6}{|c|}{ Panel C: Capital flow autocorrelation } \\
\hline \multicolumn{6}{|c|}{ Foreign net equity purchases } \\
\hline \multirow{3}{*}{$\begin{array}{l}\text { Net Purchases Measure } \\
\text { Base }\end{array}$} & $(\rho=0)$ & $(\rho=0.5)$ & Data Mean & Data Range & \\
\hline & 0.004 & 0.066 & 0.362 & $0.099-0.640$ & \\
\hline & $(0.000)$ & $(0.000)$ & $(0.000)$ & & \\
\hline \multirow[t]{2}{*}{ Scaled - Market Cap } & -0.008 & -0.010 & 0.205 & $0.029-0.647$ & \\
\hline & $(0.000)$ & $(0.000)$ & $(0.000)$ & & \\
\hline
\end{tabular}


Table 3: Country-level regularities. This table reports country-level regularities in the model and in the data. Panel A reports coefficients, p-values of the hypothesis that the coefficients differ from zero (in parenthesis), and $\mathrm{R}^{2}$ from regressions of capital flows on foreign returns in the data and in the model using robust least squares (MM estimation). Capital flows are measured both as foreign net purchases of equity and as active portfolio reallocations. Panel B shows the value of home stock held as a proportion of wealth, for the model simulations and for the data. Panel $\mathrm{C}$ gives the median value generated by the model for asset holdings by the home investor and for changes in his holdings of each asset class. For the home investor, the panel reports the median number of home and foreign equity shares and the median number of home and foreign futures held. The table also gives the median of the absolute value of changes in his holdings of each asset class, as measures of the stock and futures trading volumes.

\begin{tabular}{|c|c|c|c|c|c|c|}
\hline \multicolumn{7}{|c|}{ Panel A: Capital flow and stock return } \\
\hline & \multicolumn{3}{|c|}{ Capital flows } & \multicolumn{3}{|c|}{ Capital flows - scaled } \\
\hline & $(\rho=0)$ & $(\rho=0.5)$ & (Data) & $(\rho=0)$ & $(\rho=0.5)$ & (Data) \\
\hline \multirow[t]{2}{*}{ Brennan-Cao coef } & 0.575 & 0.734 & 0.387 & 0.541 & 0.952 & 0.224 \\
\hline & $(0.000)$ & $(0.000)$ & $(0.000)$ & $(0.000)$ & $(0.000)$ & $(0.038)$ \\
\hline \multirow[t]{4}{*}{ Adjusted $\mathrm{R}^{2}$} & 0.016 & 0.015 & 0.085 & 0.001 & 0.002 & 0.035 \\
\hline & \multicolumn{5}{|c|}{ Panel B: Home-equity preference } & \\
\hline & \multirow{2}{*}{\multicolumn{2}{|c|}{$\begin{array}{l}\text { No foreign sentiment } \\
(\rho=0) \quad(\rho=0.5)\end{array}$}} & \multirow{2}{*}{\multicolumn{2}{|c|}{$\begin{array}{l}\text { Foreign sentiment } \\
(\rho=0) \quad(\rho=0.5)\end{array}$}} & \multicolumn{2}{|c|}{ Data } \\
\hline & & & & & (Mean) & (Range) \\
\hline \multirow[t]{4}{*}{$\begin{array}{l}\text { Home equity } \\
\text { share of wealth }\end{array}$} & 0.500 & 0.500 & 0.596 & 0.566 & 0.745 & $0.651-0.803$ \\
\hline & \multicolumn{6}{|c|}{ anel C: Holdings of financial assets and trading volume } \\
\hline & & & \multirow{2}{*}{\multicolumn{2}{|c|}{$\begin{array}{l}\text { No foreign sentiment } \\
(\rho=0) \quad(\rho=0.5)\end{array}$}} & \multicolumn{2}{|c|}{ Foreign sentiment } \\
\hline & & & & & $(\rho=0)$ & $(\rho=0.5)$ \\
\hline \multicolumn{3}{|c|}{ Number of home shares held } & 0.500 & 0.500 & 0.635 & 0.637 \\
\hline \multicolumn{3}{|c|}{ Number of foreign shares held } & 0.500 & 0.500 & 0.366 & 0.363 \\
\hline \multicolumn{3}{|c|}{ Number of home futures held } & 0.000 & 0.000 & -0.021 & -0.040 \\
\hline \multicolumn{3}{|c|}{ Number of foreign futures held } & 0.000 & 0.000 & 0.021 & 0.040 \\
\hline \multicolumn{3}{|c|}{ Trading volume of stocks } & 0.000 & 0.000 & 0.073 & 0.063 \\
\hline \multicolumn{3}{|c|}{ Trading volume of futures } & 0.000 & 0.000 & 0.027 & 0.028 \\
\hline
\end{tabular}


Table 4: Firm-level regularities. This table reports firm-level regularities in the model and in the data. Panel A reports coefficients, p-values (in parenthesis), and $\mathrm{R}^{2}$ from regressing the excess equity return of a firm (Firm C) on that of its home market (Country A) and the foreign market (Country B). The first two columns give the statistics from the simulated model without and with foreign sentiment, respectively, while the third column calculates their percentage changes due to sentiment, and the fourth column contains the data estimates. Panel B reports the firm's mean percentage change in price and the mean change in return due to cross-listing both in the model with foreign sentiment and in the data. Without foreign sentiment, cross-listing would have no impact in the price or return of the cross-listing firm.

\begin{tabular}{lcccc}
\hline \hline \multicolumn{5}{c}{ Panel A: Factor model } \\
\hline & $\begin{array}{c}\text { No foreign } \\
\text { sentiment }\end{array}$ & $\begin{array}{c}\text { Foreign } \\
\text { sentiment }\end{array}$ & $\begin{array}{c}\text { Percentage } \\
\text { change }\end{array}$ & Data \\
\hline Home excess return & 0.473 & 0.515 & 8.858 & 0.861 \\
& $(0.000)$ & $(0.000)$ & & $(0.000)$ \\
Foreign excess return & 0.473 & 0.485 & 2.452 & 0.241 \\
& $(0.000)$ & $(0.000)$ & & $(0.011)$ \\
Adjusted R ${ }^{2}$ & 0.837 & 0.927 & 10.780 & 0.003 \\
\hline \multicolumn{5}{c}{ Panel B: Impact of cross-listing } \\
& \multicolumn{3}{c}{ Price change } & Return change \\
& Foreign & Data & Foreign & Data \\
& sentiment & 3.418 & -0.142 & -0.194 \\
\hline \hline
\end{tabular}


Table 5: Regularities and DOO Proxies. Panel A reports coefficients from pooled Brennan-Cao regressions where country groups are sorted by Low, Medium, and High absolute values of $a_{1}$, from initial time series regressions by country given by: $N P_{t}^{i}=a_{0}^{i}+a_{1}^{i} D_{t}+u_{t}^{i}$, where $N P_{t}^{i}$ represents US net purchases of country $i$, and $D_{t}$ is a proxy for DOO at time $t$. Panel B reports estimates from cross-sectional regressions of the absolute value of the difference between home and foreign (US) coefficients on the absolute value of the DOO proxy coefficients. The data are based upon initial time series regressions of individual firm returns on their respective home and foreign returns and DOO proxies that provide the cross-sectional series of coefficients on home and US markets, defined as $\beta_{\text {Home }}$ and $\beta_{U S}$, respectively. Panel C reports coefficients on DOO proxies in regressions of non-US stock returns on a constant, their home market return, on the foreign (US) market return, and on various proxies, all pre- and post- cross-listing in the US market. In all panels, the DOO proxies are: the difference between the 75th and 25th percentile of forecasts for US GDP, Non-Residential Investment, (NR INV), and Residential Investment (R INV); the variance of GDP forecasts (V GDP); and the US and Global Sentiment Indices (US Sent and G Sent, respectively). Standard errors are in parenthesis. ${ }^{* *}$ indicates significant at $5 \%$ MSL, and * indicates significant at $10 \%$ MSL.

\begin{tabular}{|c|c|c|c|c|c|c|}
\hline \multicolumn{7}{|c|}{ Panel A: Brennan-Cao Coefficients by Groups Sorted on DOO Sensitivity } \\
\hline Country Group & GDP & NR INV & R INV & V GDP & US Sent & G Sent \\
\hline \multirow[t]{2}{*}{ Group 1 (Low $\left.\left|\widehat{a_{1}}\right|\right)$} & $0.005^{* *}$ & $0.019^{* *}$ & $0.003^{* *}$ & $0.008^{* *}$ & $0.007^{* *}$ & $0.005^{* *}$ \\
\hline & $(0.002)$ & $(0.004)$ & $(0.001)$ & $(0.002)$ & $(0.003)$ & $(0.001)$ \\
\hline \multirow[t]{2}{*}{ Group 2 (Medium $\left.\left|\widehat{a_{1}}\right|\right)$} & $0.021^{* *}$ & $0.020^{* *}$ & $0.036^{* *}$ & $0.020^{* *}$ & $0.018^{* *}$ & $0.014^{* *}$ \\
\hline & $(0.004)$ & $(0.005)$ & $(0.006)$ & $(0.004)$ & $(0.004)$ & $(0.003)$ \\
\hline \multirow[t]{2}{*}{ Group $3\left(\right.$ High $\left.\left|\widehat{a_{1}}\right|\right)$} & $0.096^{* *}$ & $0.087^{* *}$ & $0.097^{* *}$ & $0.106^{* *}$ & $0.084^{* *}$ & $0.140^{* *}$ \\
\hline & $(0.015)$ & $(0.015)$ & $(0.016)$ & $(0.015)$ & $(0.014)$ & $(0.017)$ \\
\hline \multicolumn{7}{|c|}{ Panel B: Cross-Sectional Regression of $\left|\beta_{H o m e}-\beta_{U S}\right|$ on DOO Sensitivity } \\
\hline DOO Proxy & GDP & NR INV & R INV & V GDP & US Sent & G Sent \\
\hline \multirow[t]{2}{*}{ DOO Sensitivity } & $0.178^{* *}$ & $0.113^{* *}$ & $0.378^{* *}$ & $0.107^{* *}$ & $1.312^{* *}$ & $0.291^{* *}$ \\
\hline & $(0.001)$ & $(0.001)$ & $(0.002)$ & $(0.001)$ & $(0.014)$ & $(0.009)$ \\
\hline \multicolumn{7}{|c|}{ Panel C: Changes in Sensitivity to DOO Across Cross-Listing Events } \\
\hline DOO Proxy & GDP & NR INV & R INV & V GDP & US Sent & G Sent \\
\hline \multirow[t]{2}{*}{ Before: $b_{D}^{P R E}$} & -0.063 & -0.041 & -0.028 & -0.078 & -0.007 & $0.075^{* *}$ \\
\hline & $(0.140)$ & $(0.163)$ & $(0.161)$ & $(0.132)$ & $(0.139)$ & $(0.030)$ \\
\hline \multirow{2}{*}{ Change: $b_{D}^{P O S T}-b_{D}^{P R E}$} & $0.824^{* *}$ & $0.410^{*}$ & $0.968^{* *}$ & $0.763^{* *}$ & -0.142 & $-0.083^{* *}$ \\
\hline & $(0.289)$ & $(0.220)$ & $(0.293)$ & $(0.265)$ & $(0.233)$ & $(0.041)$ \\
\hline
\end{tabular}

